\title{
Host-Mycobacterium avium subsp. paratuberculosis interactome reveals a novel iron assimilation mechanism linked to nitric oxide stress during early infection
}

\author{
Elise A Lamont ${ }^{1 *}$, Wayne W X $\mathrm{u}^{3}$ and Srinand Sreevatsan ${ }^{1,2^{*}}$
}

\begin{abstract}
Background: The initial interaction between host cell and pathogen sets the stage for the ensuing infection and ultimately determine the course of disease. However, there is limited knowledge of the transcripts utilized by host and pathogen and how they may impact one another during this critical step. The purpose of this study was to create a host-Mycobacterium avium subsp. paratuberculosis (MAP) interactome for early infection in an epithelium-macrophage co-culture system using RNA-seq.

Results: Establishment of the host-MAP interactome revealed a novel iron assimilation system for carboxymycobactin. Iron assimilation is linked to nitric oxide synthase-2 production by the host and subsequent nitric oxide buildup. Iron limitation as well as nitric oxide is a prompt for MAP to enter into an iron sequestration program. This new iron sequestration program provides an explanation for mycobactin independence in some MAP strains grown in vitro as well as during infection within the host cell. Utilization of such a pathway is likely to aid MAP establishment and long-term survival within the host.

Conclusions: The host-MAP interactome identified a number of metabolic, DNA repair and virulence genes worthy for consideration as novel drug targets as well as future pathogenesis studies. Reported interactome data may also be utilized to conduct focused, hypothesis-driven research. Co-culture of uninfected bovine epithelial cells (MAC-T) and primary bovine macrophages creates a tolerant genotype as demonstrated by downregulation of inflammatory pathways. This co-culture system may serve as a model to investigate other bovine enteric pathogens.
\end{abstract}

Keywords: Mycobacterium avium subsp. paratuberculosis, Johne's disease, RNA-seq, Mycobacteria, Bovine, Macrophage, Epithelium, Co-culture, Interactome, Iron

\section{Background}

Molecular cross talk has recently been referred to as a dance of seduction that encompasses various tissues, cells and effector molecules [1,2]. This dance particularly holds true for the host-pathogen dynamic at the intestinal epithelium interface [3]. One common stratagem

\footnotetext{
* Correspondence: lamo0062@umn.edu; sreev001@umn.edu 'Department of Veterinary Population Medicine, College of Veterinary Medicine, University of Minnesota, 1971 Commonwealth Avenue, Saint Paul, MN 55108, USA

${ }^{2}$ Department of Veterinary Biomedical Sciences, University of Minnesota, Saint Paul, MN 55108, USA

Full list of author information is available at the end of the article
}

that intestinal pathogens utilize is to take advantage of or misdirect normal cell-to-cell cross talk that occurs between the intestinal epithelium and subepithelial dome (SED) macrophages [4-11].

Few studies focus on epithelium-Mycobacterium avium subsp. paratuberculosis (MAP) interactions and go beyond MAP translocation through $M$ cells due to the lack of in vitro and animal models that recapitulate pathogenesis [5,6,12-17]. Therefore, the majority of host-MAP studies center on the macrophage in part due to the intracellular lifestyle of pathogenic mycobacteria and the designation of enterocytes as bystander cells (until recently) [16,18-22]. However, we and others have shown that the epithelium

\section{Biomed Central}

(c) 2013 Lamont et al.; licensee BioMed Central Ltd. This is an open access article distributed under the terms of the Creative Commons Attribution License (http://creativecommons.org/licenses/by/2.0), which permits unrestricted use, distribution, and reproduction in any medium, provided the original work is properly cited. 
plays an active role during early infection with MAP and that epithelium processing of MAP may greatly contribute to the course of infection. Epithelium processing and interaction with bovine mammary epithelial cells (MAC-T), a surrogate for the intestinal epithelium, results in enhanced phagocytosis during secondary infection [23]. Changes to invasion phenotype due to epithelial processing are also seen with $M$. smegmatis, a saprophytic mycobacteria that is nonpathogenic [24]. M. smegmatis exposed to A549 epithelial cells had a significant increase in intracellular growth during secondary infection in THP-1 macrophages [24]. Epithelium processing of MAP may also impact which repertoire of pathogen genes are used during infection to promote its survival in its target cell, the macrophage. For example, MAP invasion into Madin-Darby Bovine Kidney (MDBK) cells, another surrogate cell type for the intestinal epithelium, upregulated an oxidoreductase (MAP3464) to regulate the Cdc42 pathway [25]. The Cdc42 pathway is also regulated by other pathogens to form filopodia and cytoskeleton rearrangement [26,27]. We have shown that MAP transcriptional profiles isolated and enriched from the ileum (IL) and mesenteric lymph nodes (MLN) from naturally infected cattle are significantly divergent from straight macrophage infection [28]. A number of reasons for this exists which includes 1) epithelial processing of MAP and 2) cross talk between the epithelium and macrophage. For instance, cross talk between the epithelium and macrophage results in the downregulation of pathogen recognition receptors (eg. Toll-like receptors 2 and 4), which creates an inflammation anergic state in intestinal macrophages and may impact which genes are needed by MAP to survive [29-32]. More recently, we have elucidated a mechanism for MAP orchestrated macrophage transepithelial migration that is reliant on phagosome maturation concomitant with IL-1 $\beta$ production at the epithelial interface during early infection [33]. Taken together these data suggest that MAP's first interaction within the host at the intestinal epithelium interface is a dynamic process that can be harnessed by the pathogen to achieve survival and dissemination within the macrophage. This interaction is unnoticed in in vitro macrophage models alone and it is likely that the MAP encountered by SED and lamina propria macrophages shows an entirely different transcriptional and proteomic profiles. Consequently, reported studies utilizing macrophage infection models are suspected to underestimate both host and MAP responses.

In order to bridge the knowledge gap between pathogen processing by various cell types and multiple layers of cross talk, a host-pathogen interactome must be established [34]. Based on our previous study using the epithelium/macrophage co-culture system during MAP infection, we expect that elucidation of the early molecular events resultant from multiple layers of cross talk is critical to understanding pathogen establishment and survival within the host. Host pathways involved during infection are expected to be influenced by cell-to-cell crosstalk and release of extrinsic factors. MAP processed by the epithelium prior to macrophage infection may utilize a different set of genes in comparison to macrophage infection a priori. This is the first study to show that pathways involved during early stages of MAP infection are influenced by pathogen processing by the epithelium and cell-to-cell cross talk. These results show an active role of the epithelium in establishment of MAP infection, which augments our knowledge of MAP pathogenesis as well as sheds light on pathways for disruption in novel vaccine designs.

\section{Results and discussion}

Infection under co-culture of different types of cells will reveal both the cell cross-talk and the host and pathogen interaction. In this study, macrophages and MAC-T cells were cultured alone or together in a transwell system and subjected to MAP infection at $30 \mathrm{~min}$. post-infection, which allowed for epithelium processing of MAP as well as multiple layers of cross-talk (Figure 1). RNA-seq was conducted on MAC-T, macrophages alone, or co-culture, with or without MAP infection. A total of 86,622,230 pair 76-base sequence reads were generated from 8 host samples and passed the quality check. More than $80 \%$ of reads were mapped on bovine reference genome. 74,019,002 pair 76-base sequence reads were generated from 4 infected and bacterial-enriched samples and approximately $15 \%$ of these reads were mapped on MAP reference genome.

\section{Extrinsic factors released by macrophages inhibit cellular growth to prevent cell death in MAC-T cells under co-culture conditions}

Contrary to the long-held assumption of the epithelium acting as a bystander in microbial infection, we have shown that pathogen invasion at the epithelium interface is a dynamic process that results in macrophage recruitment to the infection site in an epithelium/macrophage co-culture system, which may aid in pathogen establishment and survival [33]. Macrophage recruitment is most likely influenced by the type of host cell MAP first encounters and extrinsic factors secreted during cell to cell cross-talk (eg. epithelium and macrophage). RNA-seq and Ingenuity Pathway Analysis (IPA) analyses identified 876 and 136 differentially expressed genes, respectively, that were either mapped to functional networks or to canonical pathways, in MAC-T cells grown under co-culture conditions in comparison to MAC-T cells cultured alone (Additional file 1: sheets 1 and 2 and Figure 2A). The 136 genes were categorized into cellular and molecular functions, which identified macrophage influence on functions related to cell growth and proliferation, cell development, protein synthesis, cellular movement and cell death 


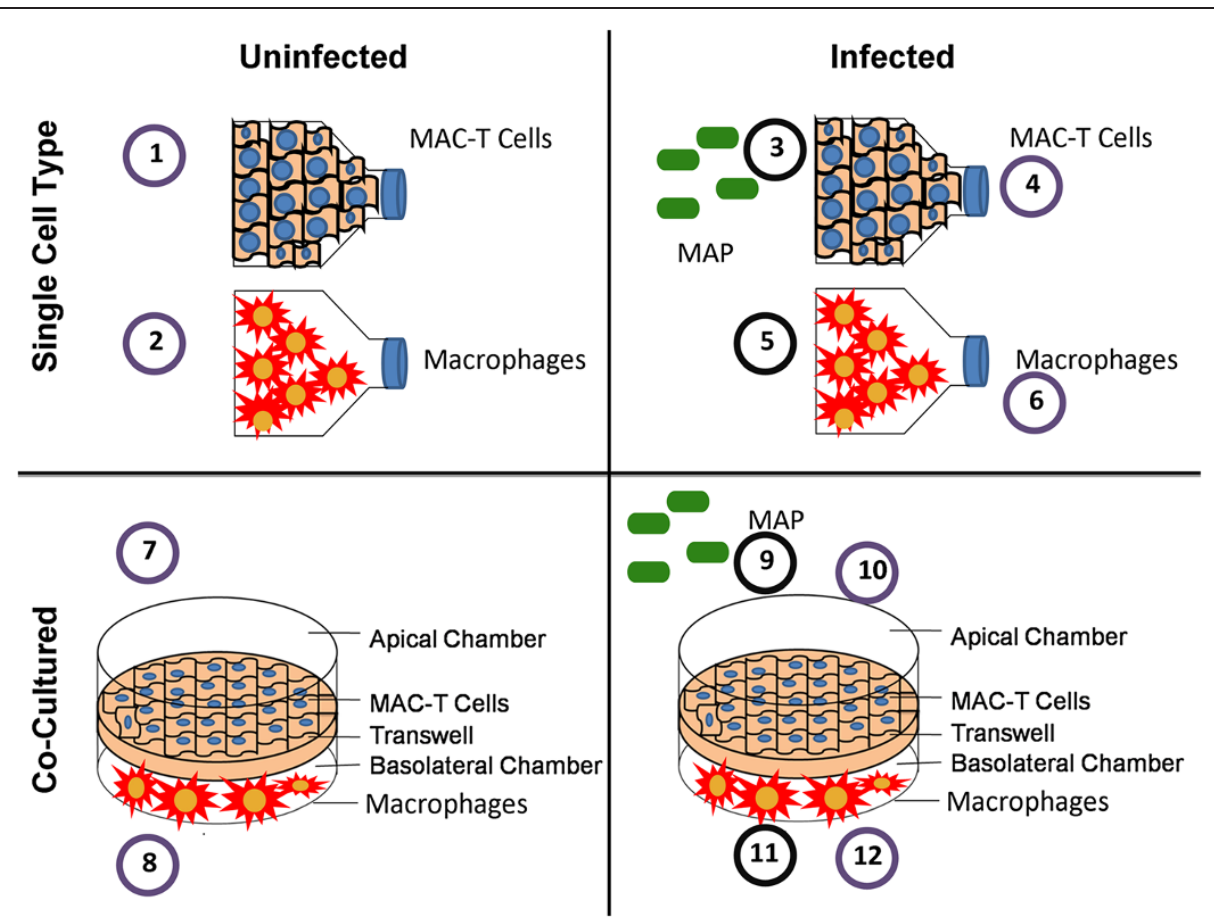

Figure 1 Experimental setup. MAC-T cells (1) and macrophages (2) were cultured separately or co-cultured (7 and 8, respectively) at a density of $\sim 2.0 \times 10^{4}$ cells $/ \mathrm{mL}$ under uninfected $(1,2,7$ and 8$)$ or MAP infected conditions $(4,6,10$ and 11$)$. RNA was extracted from host cells $(1,2,4,6,10$ and 12$)$ and pathogen located inside MAC-T cells (3 and 9) and macrophages (5 and 11) at 30 min post-infection. A total of 12 conditions (samples) were submitted for RNA-seq analysis.

(Figure 2A). Nine genes from the host (3 downregulated, 3 upregulated and 3 not differentially expressed) were selected for qT-RT-PCR validation (Figure 3). qT-RT-PCR fold changes were compared against those obtained from RNA-seq and the correlation coefficient $\left(\mathrm{r}^{2}\right)$ was calculated (Figure 3). The $\mathrm{r}^{2}$ was 0.988 , indicating a strong correlation between RNA-seq and qT-RT-PCR data (Figure 3). The majority of IPA mapped genes were downregulated in comparison to MAC-T cells cultured alone and were placed into networks involving 1) protein synthesis and cell cycle, 2) assembly and organization, cellular function and maintenance, nucleic acid metabolism, 3) cancer, dermatological diseases and conditions and lymphoid tissue structure and development and 4) cell cycle, cell morphology, and cellular assembly and organization (Additional files 2, 3, 4 and 5, respectively). Top canonical pathways (e.g. those with the most number of target molecules) were downregulated and encompassed neuregulin, insulin-1 growth factor (IGF-1), hepatocyte growth factor (HGF), and interleukin-8 (IL-8) signaling pathways (Figure 4). Downregulation of the listed canonical pathways are involved in the cessation of cell growth and inflammation. For example, activation of the neuregulin signaling pathway produces molecules that function as mitogens, differentiation agents and transforming agents in epithelial cells (Figure 4A) [35]. Also, the IGF-1 signaling pathway induces cell growth and survival via atypical protein kinase $C$ (ApkC) (Figure 4A) [36]. Again, cell growth is also a major function of the HGF pathway (Figure 4A) [37]. The IL-8 signaling pathway, which promotes inflammation, is likely downregulated as tolerance has been achieved within MAC-T cells (Figure 4A) [38,39].

\section{Co-cultured macrophages are characterized by an immune tolerant phenotype reminiscent of subepithelium dome (SED) macrophages}

Six-hundred two genes were differentially expressed between co-culture vs. macrophage alone by RNA-seq, and 77 of them were mapped by IPA (Table 1 and Additional file 1: sheet 3 ). Genes were categorized by biological and molecular functions, which included cellular function and maintenance, cellular movement, cell morphology, cell-tocell communication, and antigen presentation (Figure 2A). Like co-cultured MAC-T cells, the majority of genes identified in macrophages under co-cultured conditions were downregulated compared to macrophages cultured alone. Downregulation of genes associated with antigen presentation suggest establishment of tolerance in macrophages $[32,40]$. This is further strengthened by decreased expression in 1) inflammatory disease, 2) molecular transport, and 3) infectious disease (Additional files 6, 7 and 8, respectively). In addition, inflammatory pathways, such as 


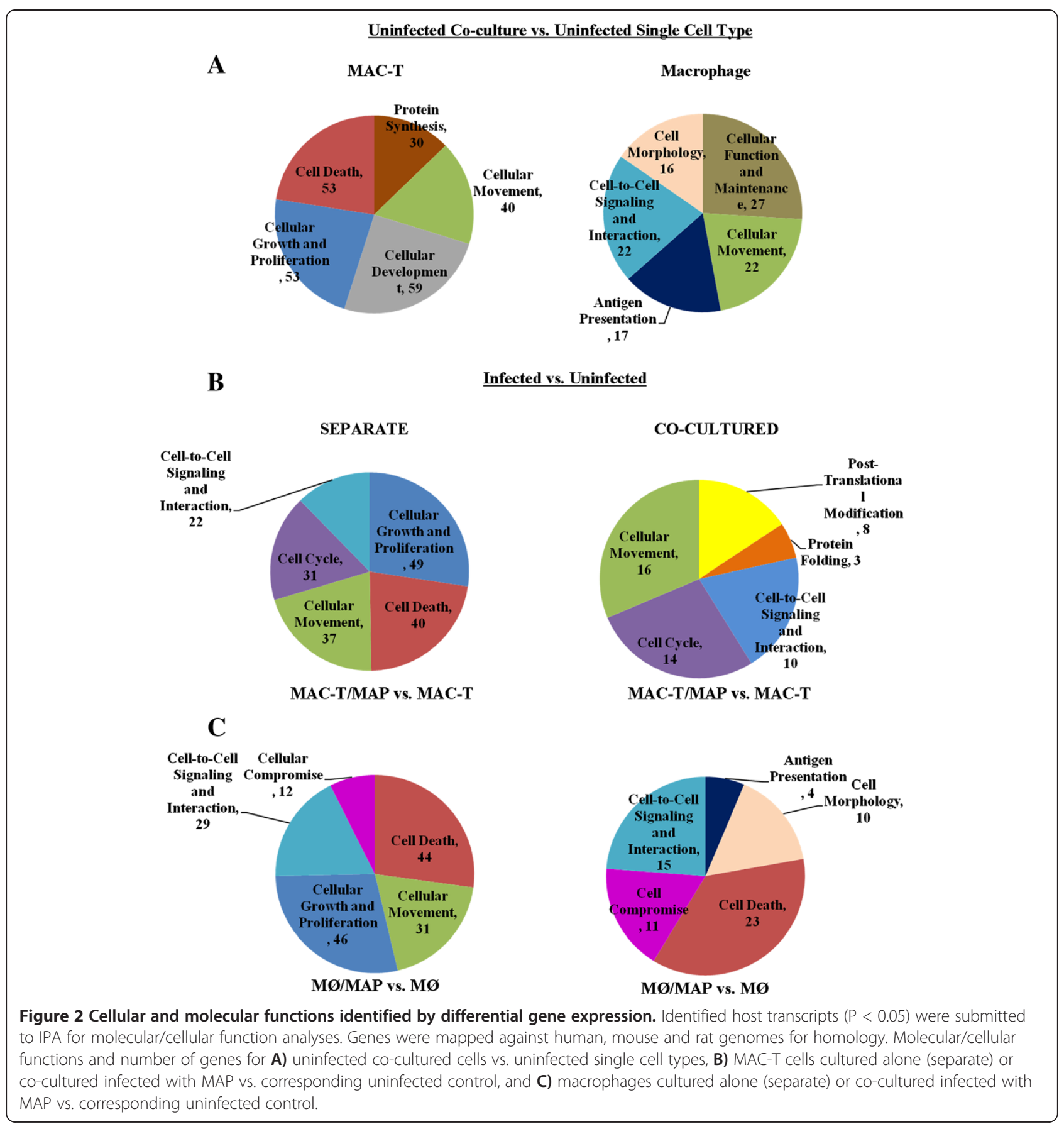

interferon signaling, were downregulated (Figure 4B). These data suggest that MAC-T cell extrinsic factors promote a tolerant phenotype that is characteristic of SED and lamina propria macrophages. Similar to macrophages co-cultured with MAC-T cells, laminia propria macrophages do not produce inflammatory cytokines such as IL-6, IL-1 and TNF- $\alpha$. Tolerance is also achieved within MAC-T cells due to extrinisic factors released during co-culture with macrophages, which is reflective of the intestinal epithelium. These data suggest that the MAC-T cell/macrophage co-culture system may serve as an in vitro model for the intestinal epithelium to study MAP-host interactions. Future studies should include further characterizations of co-cultured macrophages including the presence of macrosialin (CD86) and response to TLR angonists.

\section{MAC-T cells infected with MAP downregulate complement} receptor and have enhanced interferon activity

Five hundred and forty-seven genes (179 genes mapped using IPA) were differentially expressed in MAC-T cells 


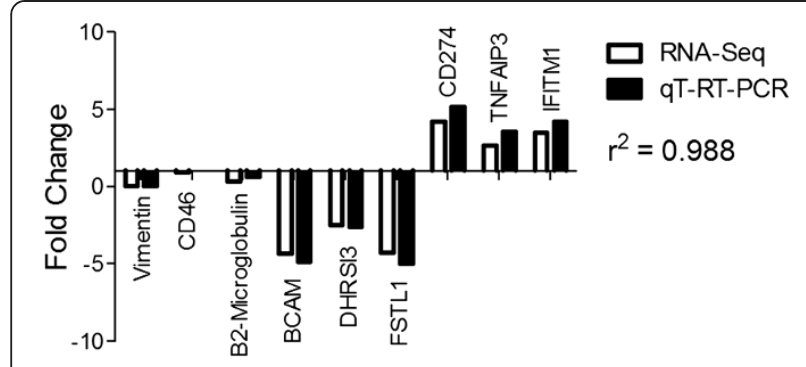

Figure 3 qT-RT-PCR analysis of selected genes. A total of nine host genes (3 downregulated, 3 not differentially expressed, and 3 upregulated) were selected for qT-RT-PCR validation. QT-RT-PCR was conducted in triplicate and the mean was graphed. The correlation coefficient $\left(r^{2}\right)$ was calculated using GraphPad Prism software.

infected with MAP in contrast to 806 genes (52 genes mapped using IPA) found in infected MAC-T cells under co-cultured conditions (Table 1, Additional file 1: sheet 4 and Figure 2B). Separate biological functions used by infected co-cultured MAC-T cells included protein folding and post-translational modification in contrast to infected MAC-T cells alone which contained cell death function (Figure 2B). The majority of upregulated genes under co-cultured conditions were involved in cellular growth and proliferation (Additional file 9) and DNA replication, recombination and repair in individual cell type culture (Additional file 10). Canonical pathway analysis revealed genes involved in PRR and interferon signaling under co-culture (Figure 4A). PRR signaling was limited to the complement receptor, which was downregulated in response to MAP infection (Figure 4A). Several reports indicate that complement receptor is used by pathogenic mycobacteria to gain entry into host cells; however, these studies focused on mycobacteriamacrophage interaction only [41-43]. It is possible that MAP uses an alternative entry route as genes associated with complement were also not upregulated in infected MAC-T cells cultured alone when compared to the uninfected control. MAP may downregulate the complement receptor in MAC-T cells co-cultured with macrophages in order to avoid immune recognition and potential clearance, which may occur due to the increased gene activity in co-cultured MAC-T cells compared to single cell type culture (Table 1). As opposed to a pathogen driven mechanism, the host may downregulate the complement receptor in order to prevent MAP invasion. In order to determine which scenario is correct a study utilizing multiple complement blocking strategies will be necessary. A common host mechanism employed under co-culture and single cell type culture conditions during MAP infection is the upregulation of genes found in the interferon signaling pathway (Figure 4A). Infected co-cultured MAC-T cells upregulated $2^{\prime}-5$ '-oligoadenylate (OAS-1), myxovirus resistance-1 (MX1) and interferon-induced protein with tetratricopeptide repeats 3 (IFIT3) (Figure 4A). MAP infected MAC-T cells alone also upregulated OAS-1, MX1 and IFIT3; however, the host cell had increased expression of Signal Transducers and Activators of Transcription (STAT1) and interferon regulatory factor 9 (IRF9) genes (Figure 4A). 2' $5^{\prime}$ - oligoadenylate synthestase 2

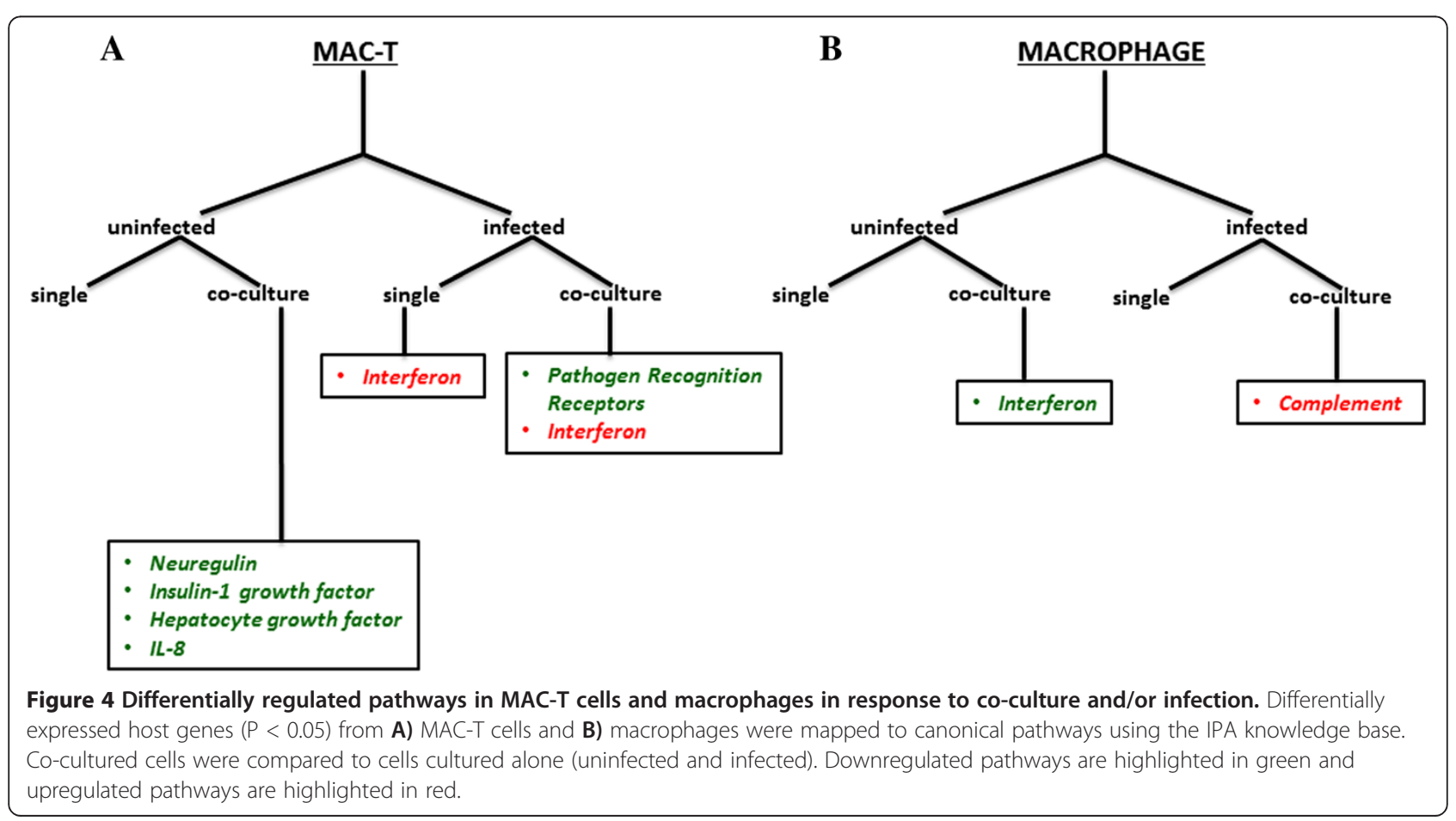


Table 1 Host differential gene expression and comparisons

\begin{tabular}{|c|c|c|c|c|}
\hline Comparison & All genes & Upregulated & Downregulated & Causation \\
\hline Infected vs. Uninfected MAC-T cells & 547 & 232 & 315 & MAP infection $(\boldsymbol{A})$ \\
\hline Infected vs. Uninfected Co-cultured MAC-T cells & 806 & 370 & 436 & $\begin{array}{l}\text { MAP infection with extrinsic factors from } \\
\text { macrophages }(\boldsymbol{B})\end{array}$ \\
\hline Infected vs. Uninfected Macrophages & 488 & 342 & 146 & MAP infection (C) \\
\hline Infected vs. Uninfected Co-cultured Macrophages & 570 & 263 & 307 & $\begin{array}{l}\text { MAP infection with extrinsic factors from } \\
\text { MAC-T cells (D) }\end{array}$ \\
\hline Infected Co-culture MAC-T cells vs. Infected MAC-T cells & 695 & 594 & 101 & $\begin{array}{l}\text { MAP infection and extrinsic factors from } \\
\text { macrophages }(\boldsymbol{E})\end{array}$ \\
\hline Infected Co-cultured Macrophages vs. Infected Macrophages & 826 & 452 & 374 & $\begin{array}{l}\text { MAP infection and extrinsic factors from } \\
\text { MAC-T cells }(\boldsymbol{F})\end{array}$ \\
\hline Infected Co-cultured MAC-T cells vs. Uninfected MAC-T cells & 876 & 751 & 125 & Extrinsic factors from macrophages (G) \\
\hline Infected Co-cultured Macrophages vs. Uninfected Macrophages & 602 & 347 & 255 & $\begin{array}{l}\text { Extrinsic factors from MAC-T cells }(\boldsymbol{H}) \text { and } \\
\text { MAP infection }(\boldsymbol{C})\end{array}$ \\
\hline
\end{tabular}

(OAS-2), a double stranded RNA (dsRNA) binding protein, is commonly associated with an antiviral response, which is characterized by downstream interferon (IFN) signaling. Like dsRNA viruses, MAP may capitalize on OAS-2 manipulation in order to evade the host innate immune response. For example, nuclear oligomerization domain 2 (NOD2), a cytoplasmic pathogen recognition receptor that detects muramyl dipeptide (MDP; a hydrolyzed product of bacterial peptidoglycan), binds to OAS-2 to enhance RNase- $\mathrm{L}$, an antiviral endoribonuclease, activity and subsequent IFN production [44]. IFN production has been linked with control of mycobacterial dissemination $[45,46]$. Interestingly, NOD2 has recently been recognized as a PRR for RNA viruses and RNase-L has been reported to be involved in clearance of intracellular bacteria $[47,48]$. Dampening of the NOD2-OAS-2 pathway may represent a universal mechanism in intracellular pathogen survival by innate immune evasion. STAT-1 is also linked to IFN production and its impairment leads to disseminated disease [49]. Together these data suggest that initial infection is marked by a check and balance system in which MAP downregulates the complement receptor to prevent immune recognition and the host upregulates the interferon pathway to clear MAP.

\section{Co-cultured macrophages infected with MAP upregulate the complement receptor to promote MAP entrance}

Four hundred and eighty-eight genes (169 genes mapped by IPA) were identified in MAP infected macrophages cultured alone versus 577 differentially expressed genes in MAP infected co-cultured macrophages (109 genes mapped in IPA) (Additional file 1: sheet 5 and Figure 2C). The majority of assigned biological functions were common to both culture conditions (Figure 2C). However, antigen presentation and cell morphology functions were restricted to co-cultured conditions while cellular movement was associated with single cell type culture
(Figure 2C). The cell death network was mostly downregulated in co-cultured macrophages in response to MAP infection in contrast to upregulation of cell-tocell signaling and interaction (Additional files 11 and 12, respectively). Unlike MAP infected co-cultured MAC-T cells, co-cultured macrophages upregulated the complement receptor, $\mathrm{C} 1 \mathrm{q}$, in response to MAP infection (Figure 4B). This suggests that once MAP orchestrates its exit from MAC-T cells, it preferentially utilizes the complement receptor for its own uptake into macrophages.

Liver X receptor/ Retinoid X receptor (LXR/RXR) activation pathway was identified in MAP infected macrophages cultured alone (Figure 4B). The LXR/RXR activation was shown to contribute to host protection against M. tuberculosis infection as determined by bacterial burden [50]. LXR/RXR protection may be due to its downstream proteins including nitric oxide synthetase-2 (NOS-2), interleukin 1-beta (IL-1 $\beta$ ) and matrix metallopeptidase 9 (MMP9), which are all upregulated in infected macrophages (Figure 4B).

\section{MAP residing in MAC-T cells rebuilds its cell wall}

Comparisons of MAP transcripts during MAC-T cell infection to those in macrophage infection identified 448 differentially expressed genes (Additional file 1: sheet 6 and Table 2). Network analysis confirmed the presence of $\operatorname{sug} A$ and $\operatorname{sugC}$, genes from an operon predicted to be involved in carbohydrate utilization from the host, and $u s p C$, a lipid anchor associated with the $u s p A B C$ operon that also plays a role in carbohydrate transport (Additional file 13) [51]. The sugABC operon, an $\mathrm{ABC}$ transporter, is best characterized in $M$. tuberculosis and is composed of a periplasmic sugar binding protein that forms a lipid anchor (LpqY), a transmembrane protein (a heterodimer of sugA and $\operatorname{sugB}$ ) and a terminal ATP-binding cytoplasmic protein $(\operatorname{sugC})$. It was previously thought that $\operatorname{sug} A B C$ served to transport maltose or matodextrins; however, Edson had 
Table 2 MAP differential gene expression and comparisons

\begin{tabular}{|c|c|c|c|c|}
\hline Comparison & All genes & Upregulated & Downregulated & Causation \\
\hline $\begin{array}{l}\text { Infected Co-Cultured MAC-T cells (7) vs. } \\
\text { Uninfected MAC-T cells (3) }\end{array}$ & 215 & 125 & 90 & Extrinsic factors from Macrophages $(\boldsymbol{J})$ \\
\hline $\begin{array}{l}\text { Infected Co-cultured Macrophages (8) vs. } \\
\text { Uninfected Macrophages (4) }\end{array}$ & 15 & 13 & 2 & Extrinsic factors from MAC-T cells $(\boldsymbol{K})$ \\
\hline
\end{tabular}

shown that both $M$. tuberculosis and M. smegmatis were incapable of growth when supplied with maltose as the sole carbon source [52-54]. The literature also indicates that host carbohydrate utilization by pathogenic mycobacteria is unlikely as the phagosome is carbohydrate poor and that host lipids provide the critical carbon and energy sources for growth $[55,56]$. It is likely that the stage of infection may determine carbohydrate availability within the phagosome. For example, Schnappinger et al. state that "there is no one phagosome" and transcriptomic profiles change concomitantly with time. In the study performed by Schnappinger et al., RNA was collected from intraphagosomal mycobacteria at 4, 24, and $48 \mathrm{~h}$ post infection as opposed to an earlier time point, such as this study, representing initial infection, which may impact carbohydrate availability [55]. Going beyond host carbohydrate metabolism, mycobacterial sugar transport systems have been implicated in virulence since transposon mutants of sugar transporters have a growth defect in macrophage and mice models [51,57]. Recently, Kalscheuer et al. has shown a novel role for LpqY-SugA-SugB-SugC in cell wall maintenance via disaccharide trehalose retrograde recycling [58]. Kalscheuer et al. demonstrated specific binding of LpqY to trehalose and subsequent uptake into the SugABC transporter. In the newly devised sugar transporter model, trehalose-containing molecules (TMM) are released during cell wall biosynthesis and are processed by mycolyl transferases from the antigen 85 complex, which result in the incorporation of the TMM mycolyl moiety to arabinogalacton (AG) for cell wall building. This process also yields the formation of trehalose dimycolate (TDM) and trehalose; trehalose is capable of binding onto LpqY, which initiates trehalose transport into the cell's cytoplasm via SugABC [58]. Once inside the cytoplasm trehalose may interact with mycolic acids by an unknown mechanism to produce TMM that is exported into the extracellular milieu to re-start the cycle [58]. The authors suggest that trehalose recycling may be necessary to maintain sugars for mycolic acid biosynthesis and as an alternative carbon source [58]. We hypothesize that the MAP sugar transport system also serves a similar function as described for the M. tuberculosis LpqY-SugA-SugB-SugC pathway. Both MAP and $M$. tuberculosis operons are identically organized; however, our network lacks $l p q$ and $\operatorname{sugB}$ (Figure 5). Although present in our MAP gene data sets, $\operatorname{sugB}$ was not considered for analysis as its p-value at 0.8 was not statistically significant (Additional file 1: sheet 6). As mentioned above, the MAP sugar transport network includes $u s p C$, which serves the same function as $\operatorname{lpq} Y$ in the usp $A B C$ operon. Protein BLAST comparisons show that UspC and LpqY are 67\% identical, share bacterial extracellular solute-binding protein motifs, and have a predicted function as periplasmic solute binding lipoproteins. We suggest that $u s p C$ may also be used in the $\operatorname{sug} A B C$ pathway as a TM binding protein (Figure 5). Further investigations into the MAP $\operatorname{sug} A B C$ operon will elucidate the importance of trehalose-recycling in virulence and determine if UspC may functionally replace LpqY. Furthermore, sugABC may provide a novel therapeutic target for pathogenic mycobacteria as trehalose and trehalose uptake systems are not present in mammals, which may reduce drug side-effects that are commonly associated with current chemotherapeutics.

Beta-oxidation is a universal MAP pathway in MAC-T cells and macrophages under co-culture and single cell type conditions

Network comparisons against known MAP pathways found in KEGG mapped several MAP genes to the betaoxidation pathway regardless of cell type and co-culture status (Additional files 13, 14 and 15 and Figure 6). The beta-oxidation pathway is utilized by mycobacteria to oxidize fatty acids as a sole carbon source in order produce acetyl-CoA, which enters into the Tricarboxylic Acid Cycle (TCA), to replicate [59,60]. fadD (CoA ligase), fadE (acylCoA dehydrogenase) and echA genes (enoyl hydratase) were found to be upregulated by MAP in MAC-T cells under single cell type culture conditions (Additional file 14 and Figure 6). The MAP profile in infected macrophages (single cell type infection) identified one fadD (MAP2833c) gene and one $f a d E$ gene (MAP3651c), indicating that betaoxidation has just initiated within macrophages (Figure 6). Comparisons of infected co-cultured MAC-T cells against infected MAC-T cells, identified additional fadE gene (MAP1458), enoyl hydratases (MAP2589 and MAP1460), and a transcriptional regulator (MAP2591) (Figure 6).

MAP undergoes translesion synthesis and double stranded break repair to insure its survival within nitrosative MAC-T cells

Two hundred and fifty-one differentially regulated MAP genes were uncovered in MAC-T co-cultured vs. 


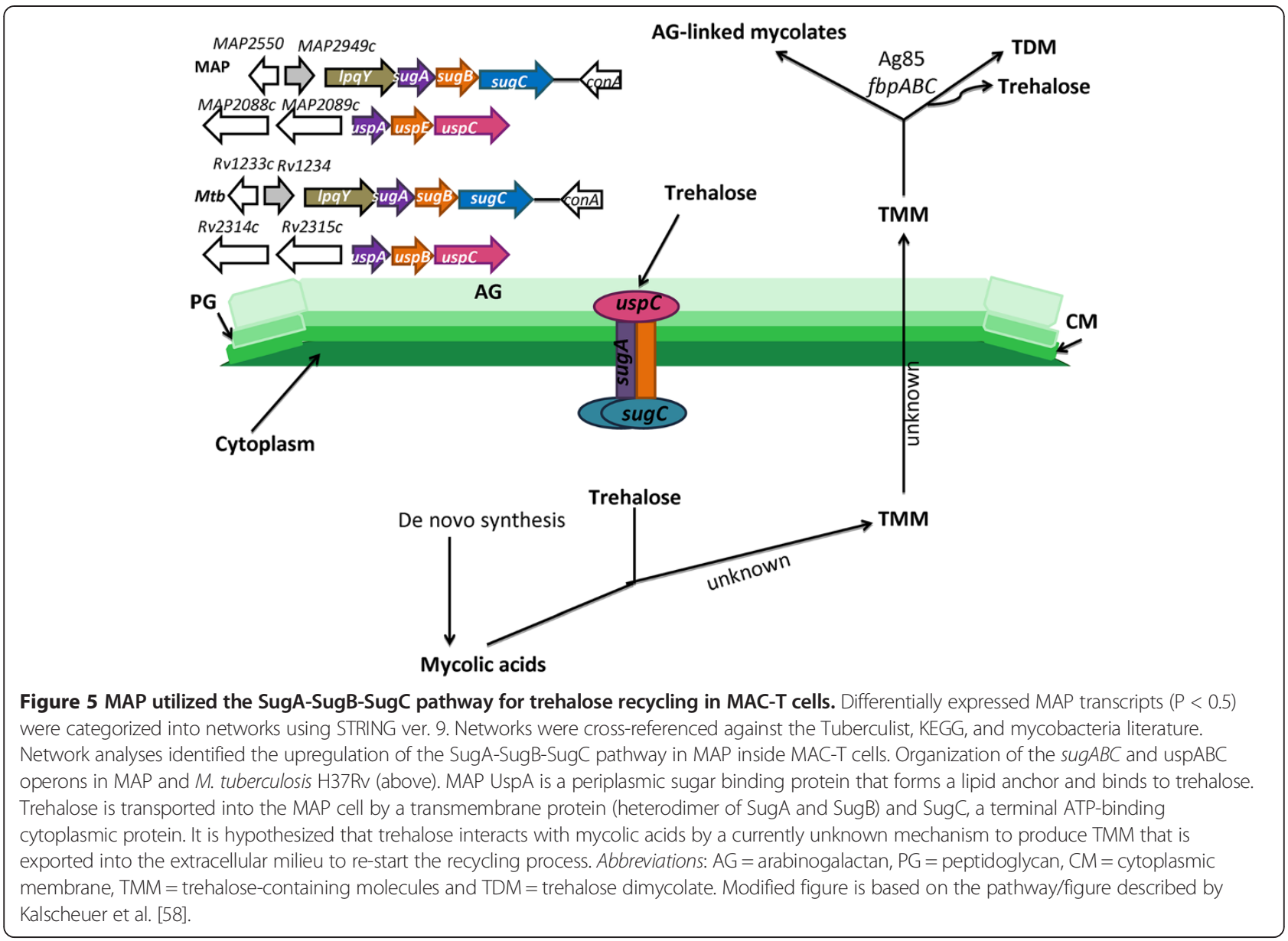

macrophage co-cultured comparisons (Additional file 1: sheet 7). Further analysis identified a major network pertaining to MAP replication (Additional file 15). The first characterized network gene, $M A P 3179 c$, was determined to function as a universal stress response gene that when bound to chromosomal DNA, initiates the SOS response (Figure 7). Further examination of the network indicated that MAP3179c became activated due to nitric oxide sensing within the bacterial cell. (Figure 7) [61]. The presence of NO is suspected to result in DNA damage. $M A P 2835 c$ has an upstream SOS binding box and like $M A P 3179 c$ is activated due to nitric oxide buildup; therefore, DNA replication is likely inhibited by a yet to be identified mechanism until DNA repair can be accomplished [62]. MAP likely overcomes the stall in DNA replication by employing A) double strand break repair and B) translesion synthesis (Figure 7). Mapping of network genes onto the double strand break repair pathway for MAP within KEGG showed MAP1078 and MAP1130 involvement. MAP1078 is responsible for dissolving the Holliday junction after 5 ' to ' 3 resection and MAP1130 forms a primosome to resume DNA replication (Figure 7). It is possible that prolonged cell exposure to NO may cause some DNA bases to become irreparable [63]. Based on our network analysis this appears to be the case; therefore, MAP conceivably employs translesion synthesis (TLS) (Additional file 15). TLS is a damage tolerance pathway that allows a cell to replicate past DNA lesions and distortions by using an error-prone or lesion bypass polymerases [64]. This process is expected to follow the Tool belt hypothesis, which has been shown in E. coli and M. tuberculosis $[65,66]$. MAP3487c (referred to as ImuB; predicted Y-family polymerase) contains a $\beta$-clamp motif that enables recruitment and rapid interchange of replication machinery proteins pertaining to DNA repair and lesion bypass polymerases (sliding clamp) at the replication fork $[66,67]$ (Figure 7). Along with resuming DNA replication, mutations will be inserted into the nascent strand. The implications of this are unclear. Nitric oxide may also interact with MAP2833c, which contains a nitrobindin binding domain that reversibly binds to nitric oxide, and cause further deleterious buildup within the cell [68]. The network implicates the involvement of MAP4216, a predicted glutathione reductase based on the presence of a pyridine nucleotide-disulphide oxidoreductase domain, as a source to defuse nitric oxide (Figure 7). Enzymes containing the 


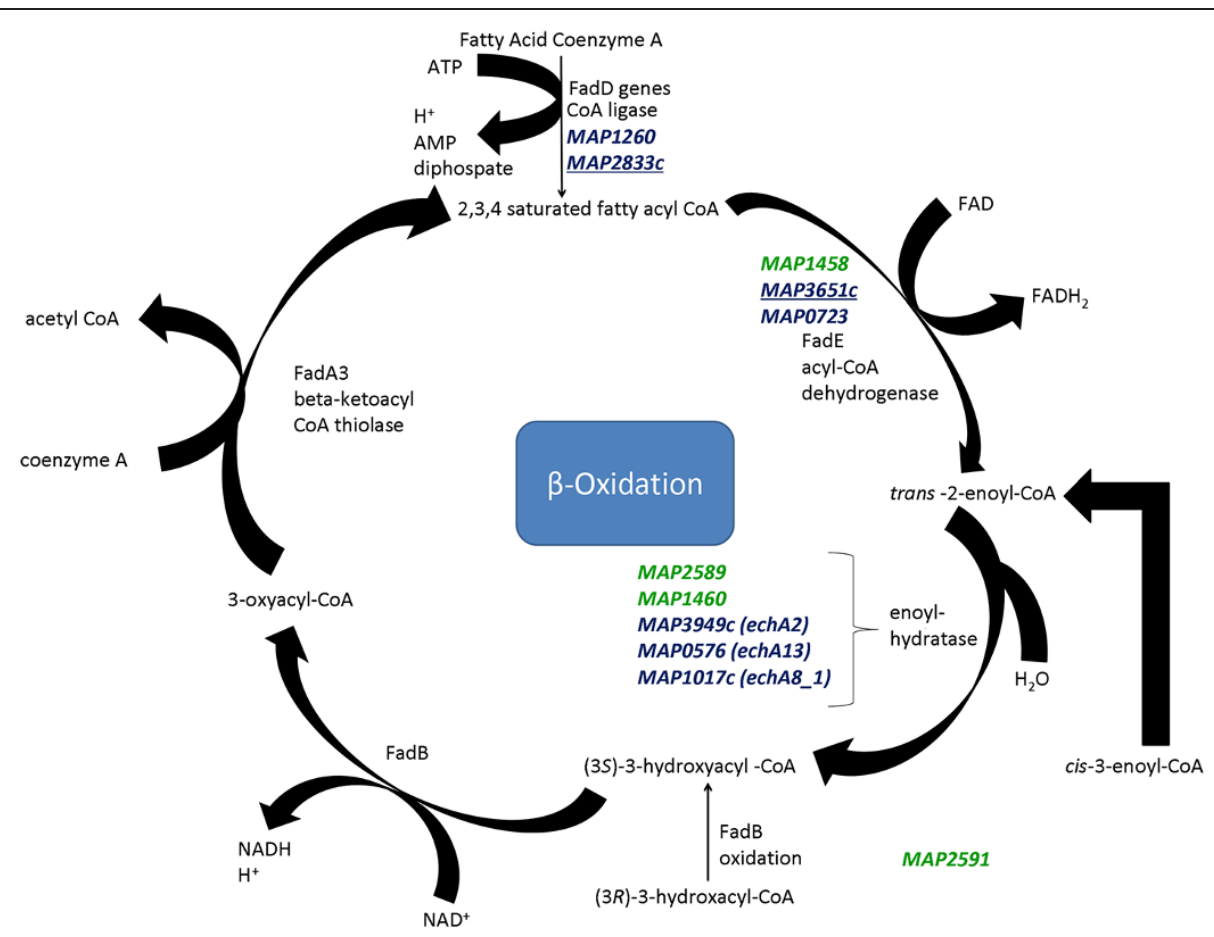

Figure 6 MAP utilizes the $\beta$-oxidation pathway under all culture conditions. MAP inside MAC-T cells (co-cultured and alone) and macrophages (cultured alone) upregulated genes involved in the $\beta$-oxidation pathway. Upregulated genes involved in $\beta$-oxidation were fadD, fadE, enoyl-hydratases, and a transcriptional regulator (MAP2591). Genes highlighted in dark blue were upregulated under single cell culture; underlined $=$ macrophage, normal text $=$ MAC-T. Genes highlighted in green were upregulated in MAC-T cells under co-cultured conditions .

pyridine nucleotide-disulphide oxidoreductase domain have been shown to protect cells from oxidative damage [69]. MAP3296c, also referred to as whiB7, is present within the network. WhiB7 from M. tuberculosis is involved in the transcription of antibiotic resistance programs including those for tetracycline, macrolide, lincosamide and aminoglycoside resistance [70-73]. In our model, WhiB7 is activated in the presence of a reducing environment caused by MAP4216. WhiB7 interacts with MAP1798, a potential antibiotic resistance protein, and MAP2674c, an antibiotic biosynthesis monooxygenase (Figure 7). Also, we show that MAP2835c, which contains a LysM (peptidoglycan binding domain) and closely resembles the cell wall hydrolase, Rv2719c, of M. tuberculosis, is upregulated. MAP2835c is hypothesized to have a role in maintenance of cell wall division despite the presence of DNA damaging agents [74-77]. These data suggest that MAP encounters a dynamic host environment that contains nitric oxide. MAP overcomes DNA damage and stops in replication by employing double strand break repair and TLS. This hostile environment also creates an opportunity for MAP to activate antibiotic resistance genes. This network has illustrated a number of potential targets for therapeutic design, including ImuB and WhiB7 (Figure 7). Further research involving mutation and deletion of the above genes will be required to validate the TLS pathway.
MAP upregulates various transporters involved in lipid and nickel import in co-cultured MAC-T cells

Two networks were identified as being associated with mammalian cell entry (mce) and dipeptide/nickel transport (Additional file 15). Studies investigating mce gene function have linked mce expression with virulence and it is also believed that pathogenic mycobacteria upregulate mce family genes to gain entry into non-phagocytic cells [78-82]. However, mce genes are structurally similar to $\mathrm{ABC}$ transporters and are also thought to play a role in lipid or other molecule import into the cell [78,83-85]. The mce network is composed of MAP0757 (mce5), an ABC transporter and permease, and MAP2113c and MAP0110, mce related genes that belong to the mce3 and mce7 [78]. The network suggests that although identified genes do not belong to the same operon that they may function together as a potential $\mathrm{ABC}$ import system. We hypothesize that MAP2113c and MAP0110 function as lipid binding domains and are either 1) tethered to the cell membrane via a lipid anchor or 2) inserts into MAP0757 (Figure 8). Once a lipid, possibly host derived, binds onto either MAP2113c or MAP0110 and is transferred to MAP0757 and is subsequently imported into the cell where it can be utilized for energy conversion (Figure 8).

Nickel/dipeptide utilization is also accomplished through an $\mathrm{ABC}$ transporter system. In this model, dppA binds 


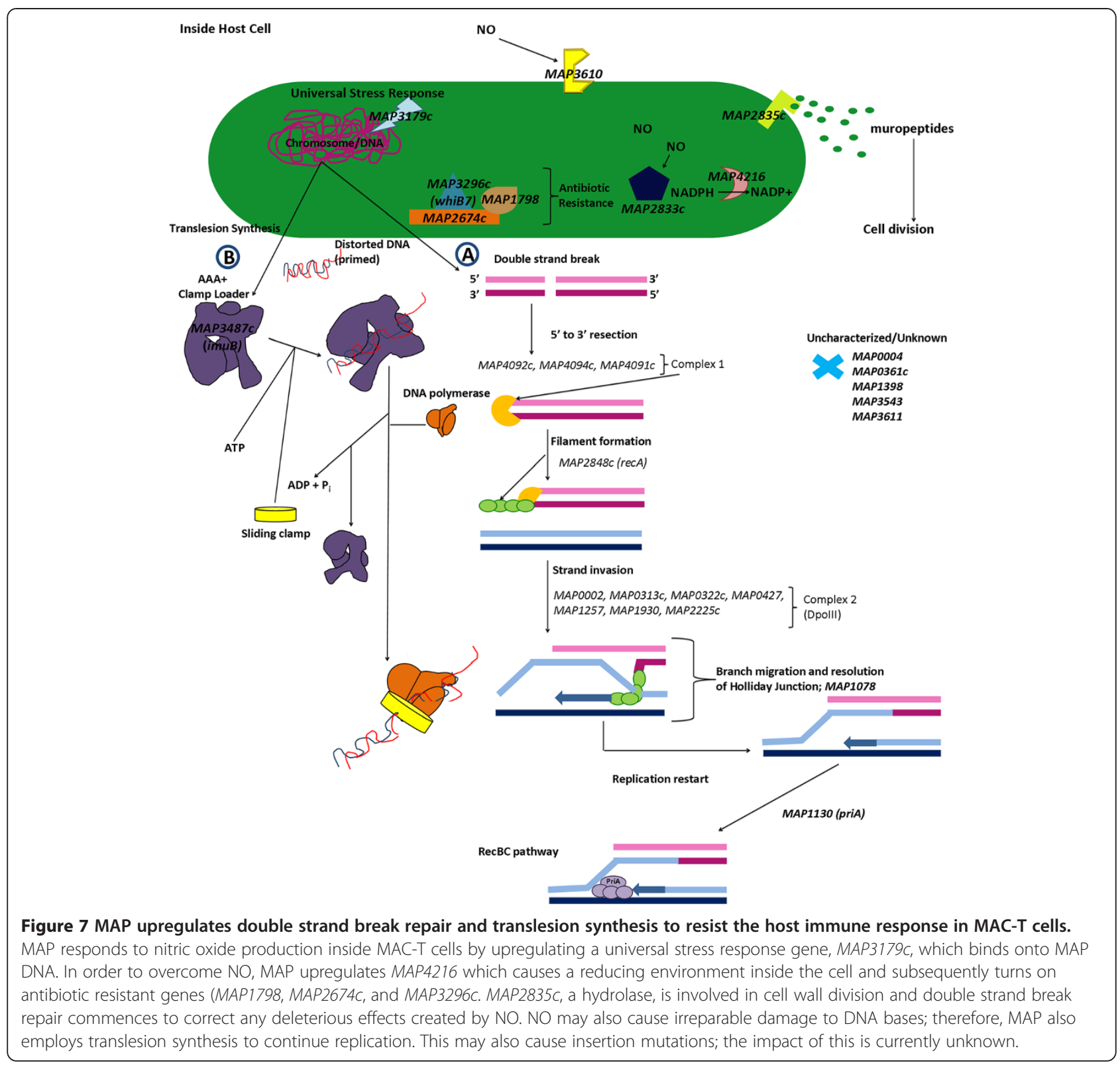

nickel/dipeptide in the extracellular milieu and transfers it to the permease, dppC (Figure 9). dppD_1 and dppD_2 represent terminal molecules in the system and drives nickel/dipeptide into the cell (Figure 9). Pathogenic mycobacteria have developed numerous systems for the importation and sensing of nickel as it is involved in cell growth and homeostasis [86,87].

\section{Defining the dance of seduction: the host-MAP interactome}

In order to link host biological processes to pathogen responses, we examined all differentially expressed genes from host and pathogen $(n=1795)$ and conducted a Kclustering analysis to determine correlations in expression.
The K-clustering analysis identified 81 host genes that shared a similar pattern profile with 77 MAP genes (Additional file 1: sheets 8 and 9 and Additional file 16). Host expression profiles were dependent upon co-culture status (Additional file 1: sheet 9). Host genes were categorized into Gene Ontology (GO) biological processes using DAVID software (Tables 3 and 4). The majority of GO processes upregulated in MAC-T cells were related to cell maintenance (e.g. cell division, cell cycle, DNA replication, etc.) while downregulated processes included the immune response and signal transduction regulation (e.g. kinase, phosphorylation and transferase activities) (Table 4 and Additional file 1: sheet 10). In contrast to differentially expressed GO biological process in MAC-T cells, 


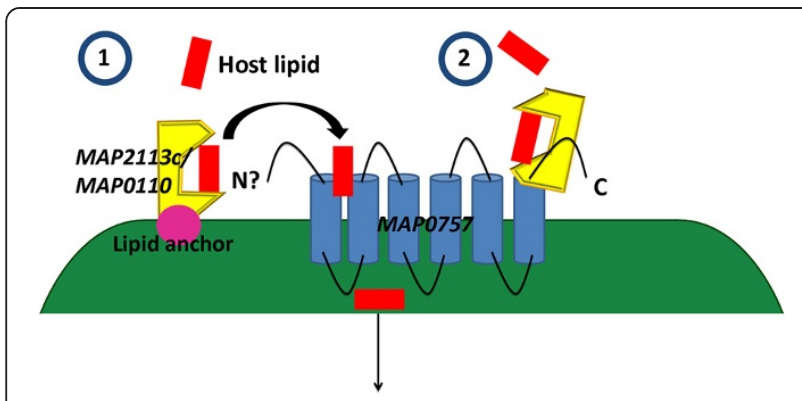

Figure 8 MAP expresses mammalian cell entry genes to import host lipids in co-cultured MAC-T cells. Network analysis identified upregulation of mce genes found in the mce5, mce3 and mce 7 operons. mce genes are hypothesized to serve a lipid transport role as they are structurally similar to ABC transporters. MAP2113c and MAP0110 are predicted to be lipid binding proteins that may be 1) connected to a lipid anchor on the cell membrane or 2) inserted into the permease, MAP0757. Importation of lipids, potentially host derived, may be utilized for energy conversion.

macrophages showed upregulation of pathways involved in pathogen elimination and host preservation (e.g. defense, immune, inflammatory, and wound responses) and downregulation of immune responses primarily associated with $2^{\prime} 5^{\prime}$ oligoadenylate synthetase and major histocompatibility class 1 (MHCI) related proteins (Table 5 and Additional file 1: sheet 11). MAP genes identified by Kcluster analysis were organized into Cluster of Orthologous Groups (COG) (Table 5 and Additional file 1: sheet 8). As expected, the majority of differentially regulated genes were categorized as an unknown function (Table 5) due to the large number of hypothetical genes within the MAP K-10 genome [88]. Other functional groups of interest included defense mechanism, replication, recombination and repair, secondary metabolites biosynthesis, energy production and conversion, and lipid transport and metabolism (Table 5). COG identification indicates that initial infection is characterized by a pathogen program specific for MAP establishment within the host as defined by bacterial replication in face of strenuous host immune and defense responses.

The 77 MAP genes constitute two significant networks (Additional file 17). Network 1 is composed of 3 upregulated genes, MAP3980, MAP1913c, and MAP2495, in MAC-T cells and macrophages (Additional file 17). Predicted functions involve sensory transduction regulation (MAP3980) and endonuclease activity for homing activity (MAP2495). MAP1913c does not contain any known structural motifs and is declared as a gene of unknown function. MAP3980 resembles $y b j N$, a sensory transduction regulator and orphan gene found in Escherichia coli $[89,90] . y b j N$ has been show to play a role in cell motility, aggregation, exopolysaccharide production, and biofilm production [89]. These functions are dependent upon $y b j N$ expression as overexpression of $y b j N$ reduced the above processes [89]. However, upregulation of $y b j N$ activated the SOS response pathway [89]. Homing endonucleases, like MAP2495, are highly-specific DNA cleaving enzymes that initiate double-stranded break repair [91,92]. Increased expression of MAP3980 and MAP2495 indicates a hostile host environment characterized by oxidative and nitrosative stresses, which is further supported by doublestranded break repair via MAP1078 and MAP1130 as well as translesion repair synthesis described in the MAC-T cell comparison to macrophages under co-culture conditions (Figure 7). This mechanism is most likely used as a survival

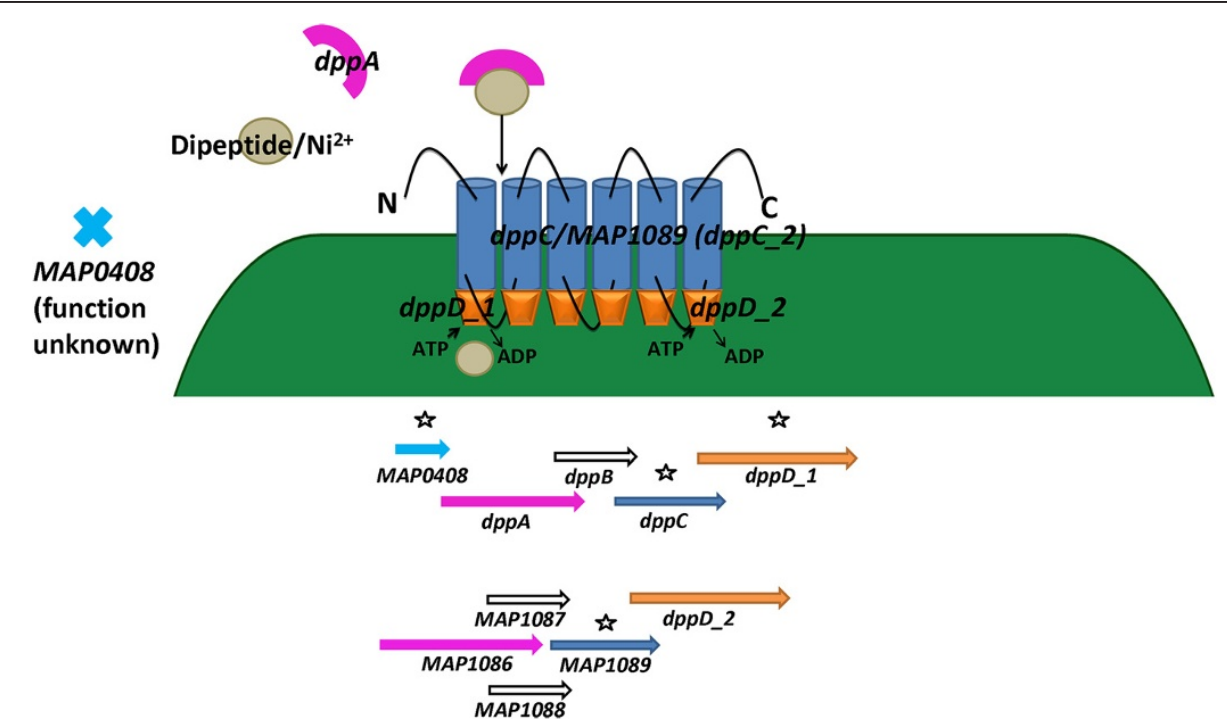

Figure 9 MAP uses a nickel/dipeptide transporter inside co-cultured MAC-T cells. An ABC transporter system is formed by MAP for nickel importation inside co-cultured MAC-T cells. DppA binds nickel/dipeptide and transports it into the cell using DppC, DppD_1, DppD_2, a permease system. The $\operatorname{dp} p A B C D$ operon (below). Genes identified in the network are noted with stars. 
Table 3 Differentially expressed Go biological processes in response to map infection inside MAC-T cells

\begin{tabular}{|c|c|c|c|c|}
\hline & GO process & Number of genes & P-Value & Benjamini score \\
\hline \multirow[t]{16}{*}{ Upregulated } & Cell cycle process & 36 & $2.42 \mathrm{E}-12$ & 2.43E-09 \\
\hline & M phase & 2 & $7.38 \mathrm{E}-12$ & $3.71 \mathrm{E}-09$ \\
\hline & Nuclear division & 15 & 8.97E-12 & $3.01 \mathrm{E}-09$ \\
\hline & Mitosis & 30 & 8.97E-12 & $3.01 \mathrm{E}-09$ \\
\hline & Cell division & 2 & $1.29 \mathrm{E}-11$ & $3.24 \mathrm{E}-09$ \\
\hline & M phase of mitotic cell cycle & 15 & $1.81 \mathrm{E}-11$ & 3.65E-09 \\
\hline & Organelle fission & 30 & $2.15 \mathrm{E}-11$ & 3.60E-09 \\
\hline & Cell cycle phase & 18 & $2.36 \mathrm{E}-11$ & 3.40E-09 \\
\hline & Cell cycle & 8 & 4.14E-11 & 5.21E-09 \\
\hline & Mitotic cell cycle & 16 & 1.17E-10 & 1.30E-08 \\
\hline & Microtubule-based process & 12 & $3.14 \mathrm{E}-05$ & 0.00315028 \\
\hline & DNA metabolic process & 15 & 3.99E-05 & 0.003643606 \\
\hline & DNA replication & 9 & 4.40E-05 & 0.003681565 \\
\hline & Microtubule-based movement & 9 & 7.00E-05 & 0.00540001 \\
\hline & DNA replication initiation & 4 & $1.80 \mathrm{E}-04$ & 0.0128323 \\
\hline & Negative regulation of molecular function & 8 & 5.69E-04 & 0.03743265 \\
\hline \multirow[t]{10}{*}{ Downregulated } & Immune response & 19 & $1.06 \mathrm{E}-05$ & 0.011956577 \\
\hline & Regulation of protein kinase activity & 10 & 1.17E-04 & 0.064589297 \\
\hline & Regulation of kinase activity & 10 & $1.76 \mathrm{E}-04$ & 0.064494576 \\
\hline & Ear development & 7 & 1.94E-04 & 0.053853857 \\
\hline & Regulation of phosphorylation & 12 & $1.96 \mathrm{E}-04$ & 0.043562316 \\
\hline & Regulation of transferase activity & 9 & 2.27E-04 & 0.042105651 \\
\hline & Regulation of cell proliferation & 15 & 2.64E-04 & 0.042029006 \\
\hline & Regulation of phosphorus metabolic process & 12 & 2.89E-04 & 0.040342208 \\
\hline & Regulation of phosphate metabolic process & 12 & $2.89 \mathrm{E}-04$ & 0.040342208 \\
\hline & Negative regulation of protein kinase activity & 6 & 3.44E-04 & 0.042649138 \\
\hline
\end{tabular}

Table 4 Differentially expressed GO biological processes in response to MAP infection inside macrophages

\begin{tabular}{|c|c|c|c|c|}
\hline & GO process & Number of genes & P-Value & Benjamini score \\
\hline \multirow[t]{13}{*}{ Upregulated } & Defense response & 18 & 1.10E-07 & $1.46 \mathrm{E}-04$ \\
\hline & Inflammatory response & 12 & 8.84E-07 & $5.84 \mathrm{E}-04$ \\
\hline & Immune response & 19 & 1.14E-06 & 5.04E-04 \\
\hline & Response to wounding & 14 & $5.02 \mathrm{E}-06$ & 0.001656 \\
\hline & Positive regulation of cellular component organization & 9 & 5.07E-06 & 0.001341 \\
\hline & Regulation of cell adhesion & 9 & 7.37E-06 & 0.001623 \\
\hline & Positive regulation of cell adhesion & 7 & $8.82 \mathrm{E}-06$ & 0.001664 \\
\hline & Positive regulation of organelle organization & 6 & 3.53E-05 & 0.005815 \\
\hline & Lipid biosynthetic process & 12 & 9.28E-05 & 0.013545 \\
\hline & Positive regulation of cell motion & 6 & 2.03E-04 & 0.026443 \\
\hline & Fatty acid biosynthetic process & 7 & $2.52 \mathrm{E}-04$ & 0.029821 \\
\hline & Regulation of cytokine biosynthetic process & 6 & 3.47E-04 & 0.037516 \\
\hline & Acute inflammatory response & 6 & $6.23 \mathrm{E}-04$ & 0.061455 \\
\hline Downregulated & Immune response & 12 & 4.92E-04 & 0.03621235 \\
\hline
\end{tabular}


Table 5 COG function

\begin{tabular}{cc}
\hline Function & Number of genes \\
\hline Defense mechanism $(\mathrm{V})$ & 1 \\
Secondary metabolites synthesis (Q) & 1 \\
Energy production and conversion (C) & 1 \\
Replication, recombination and repair (I) & 5 \\
Lipid transport and metabolism (I) & 5 \\
Function unknown (S) & 60 \\
\hline
\end{tabular}

strategy for pathogen genome stability in face of a strenuous host response [66,93-95].

Network 2 was composed of an operon (MAP3734c$3736 c$ ) and a neighboring gene (MAP3737) that were transcribed in opposite directions and suspected in iron regulation (Additional file 17). Iron is utilized by intracellular bacteria in redox reactions, electron transport, replication and other essential functions [96-98]. Due to iron limitation within the host (e.g. iron bound to transferrin, lactoferrin or ferritin), pathogenic mycobacteria have developed several strategies for iron sequestration and storage [97-100]. A critical iron acquisition mechanism is the synthesis and transport of siderophores (low-molecularweight $\mathrm{Fe}^{+3}$ chelators), which include mycobactin (cell wall associated) and carboxymycobactin (secreted) [101,102]. All genes in network 2 were found to be upregulated in both cell types (Additional file 17). However, co-cultured macrophages showed a decrease in transcription compared to macrophages cultured alone. Reduced MAP transcriptional activity within co-cultured macrophages may be due to dampening host responses caused by MAC-T cell extrinsic factors. MAP3734c-3736c and MAP3737 are designated as hypothetical genes; however, domain and motif searches determined that MAP3734c-3736c form an ABCtype multidrug transport system and MAP3737 has a Proline-Proline -Glutamate (PPE) domain. MAP3734c$3736 c$ belong to the large sequence polymorphism 14 (LSP14) and contain nucleotide binding Walker A (WA), Walker B (WB), and ABC transporter Signature Motifs (SM) at the C-terminal end [103]. Also, MAP3735c has an N-terminal Siderophore Binding Domain (SBD) that resembles substrate binding domains of siderophore uptake systems, such as the ferric enterobactin transport ATPbinding protein, FepC [54,104]. Furthermore, MAP3735c and $M A P 3736 c$ are predicted to form a heterodimer that is composed of 6 transmembrane segments in contrast to MAP3734c that forms 5 transmembrane segments. BLAST comparisons and reference to the Tuberculist database server (http://genolist.pasteur.fr/TubercuList/) listed $R v 1348$ (MAP3735c and MAP3736c have 42 and 40 per cent amino acid identity, respectively) and $R v 1349$ (MAP3734c is 34 per cent identical at the amino acid level) as orthologs to MAP3734c-MAP3736c. Rv1348 and Rv1349 were first reported to be repressed in the presence of iron by the direct regulation of the Iron dependent Regulator (ideR) and later identified as an $\mathrm{ABC}$ transport system involved in iron acquisition $[99,105]$. Rodriguez and Smith showed that mutants of $R v 1348$ and $R v 1349$ (also referred to as iron-regulated transporters (Irt) $\mathrm{A}$ and $\mathrm{B}$, respectively) failed to replicate efficiently in vitro under iron-deficient conditions, in THP-1 cells, and inside the lungs of C57/B6 mice [105]. Rodriguez and Smith reasoned that IrtA and B may be involved in mycobactin synthesis; however, the $i r t A$ mutant and $\operatorname{irt} A B$ double mutant strains produced equivalent amounts of mycobactin compared to the wild-type strain [105]. Although irt $A B$ was determined not to be involved in mycobactin synthesis, the growth defect was linked to the inability of the $\operatorname{irt} A B$ mutant to utilize iron bound carboxymycobactin (Fe-cMyco) [105]. $\operatorname{irt} A$ and $\operatorname{irt} B$ involvement in Fe-cMyco utilization is further supported by a study conducted by Farhana et al., which elucidated the $\operatorname{irt} A B$ iron trafficking mechanism utilizing recombinant Irt $A$ and IrtB packaged into liposomes and $\operatorname{irt} A$ and $\operatorname{irt} B$ knock out mutants in M. smegmatis [106]. According to the model proposed by Farhana et al., IrtAB functions as a novel carboxymycobactin cytoplasmic exporter-importer system, in which newly synthesized, non-ferrated carboxymycobactin binds specifically onto the IrtA SBD and is exported into the extracellular milieu to sequester $\mathrm{Fe}^{3+}$ [106]. Farhana et al. show that Fe-cMyco binds to an IdeR independent siderophore interacting protein, $R v 2895 c$, found on the cytoplasmic membrane that forms a two-component importer with IrtB [106]. In addition to Fe-cMyco utilization, the IrtAB carboxymycobactin importer-exporter system may prevent toxic siderophore buildup inside the bacterial cell. Based on the Farhana model, MAP3734c-MAP3736c functions as a carboxymycobactin importer-exporter system that is activated due to iron limitation within the host (Figure 10A). $M A P 3734 c$ forms a heterodimer with $M A P 3735 c$ and exports non-ferrated carboxymycobactin into the extracellular milleu, where the siderophore may sequester iron. Fe-cMyco is transported back into the cell by MAP3736c and is subsequently used for processes requiring iron (Figure 10A). It is important to note that we did not find $M A P 2960 c$, the equivalent of $R v 2895 c$, within network 2 nor in the listed MAP interactome genes. Recently the Farhana model has been brought into question due to the exclusion of confirmatory experiments such as, testing recombinant IrtB proteoliposomes for siderophore export and recombinant IrtA proteoliposomes for siderophore import, characterization of protein topology within liposomes, and creation of $\operatorname{irt} A$ and $\operatorname{irtB}$ knock out mutants in M. tuberculosis [107]. Rather than functioning as a carboxymycobactin importer-exporter system, Ryndak and others propose that Irt $A B$ forms one $A B C$ transporter necessary for Fe-carboxymycobactin and iron assimilation 


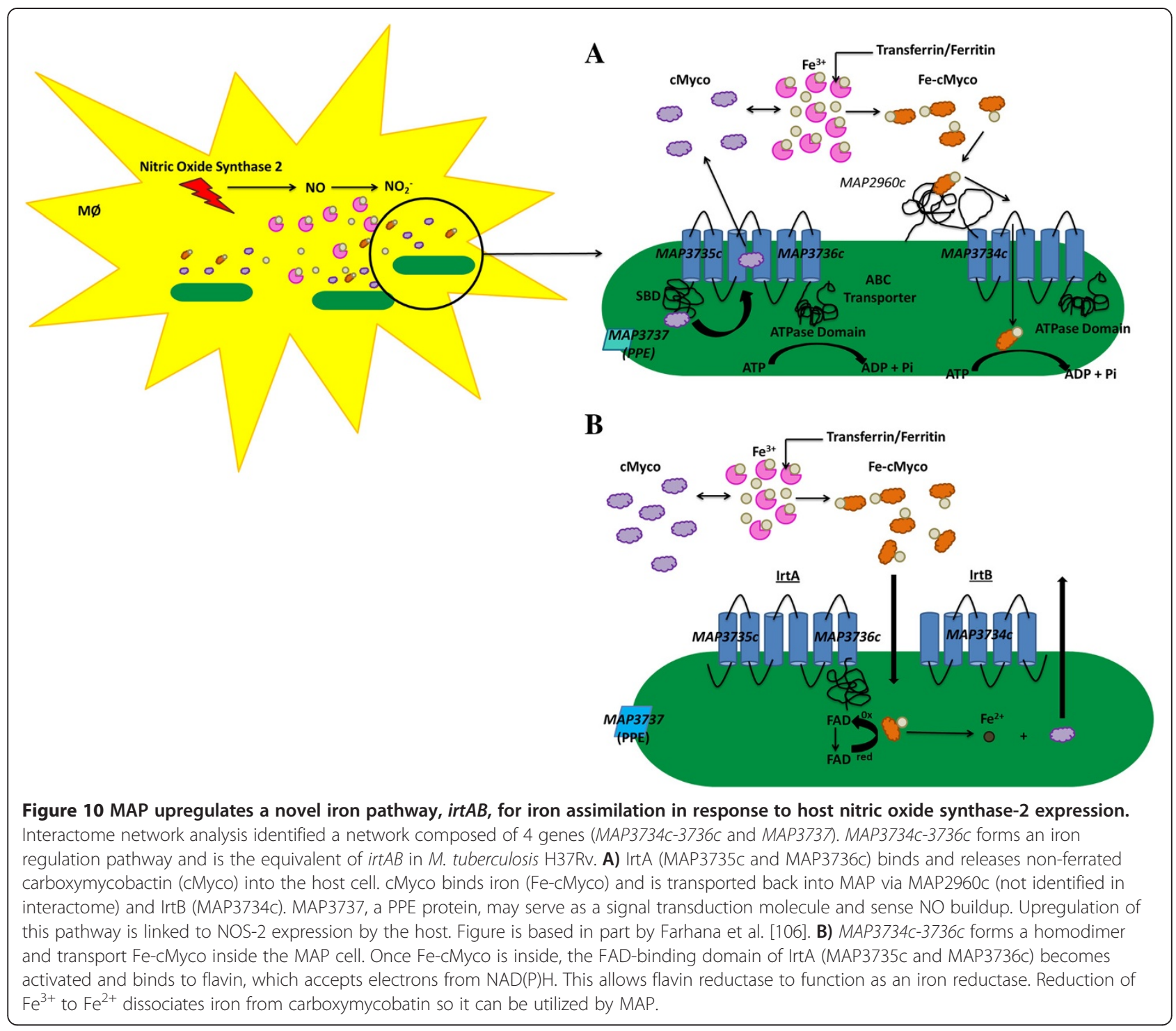

via ferric iron reduction [107]. In the study performed by Ryndak et al., the amino terminus domain was shown to contain a FAD-binding domain and when mutated abrogated IrtAB function and iron utilization [107]. The authors suggest that the Farhana model may be reflective of M. smegmatis only and has limited translation to M. tuberculosis [107]. Furthermore, Ryndak et al. state that the positive chrome azure $\mathrm{S}$ (CAS) assay from Farhana et al. is most likely due to exochelin, which composes the majority of secreted siderophores by $M$. smegmatis, and not Fe-carboxymycobactin [107]. Under the Ryndak model, MAP3734c-MAP3736c forms a single ABC transporter and the IrtA FAD binding domain functions after Fecarboxymycobactin translocation (Figure 10B). The FAD binding domain of IrtA (MAP3735c and MAP3736c) binds flavin, which is reduced by $\mathrm{NAD}(\mathrm{P}) \mathrm{H}$ and dissociates and serves as a ferric reductase and is sustained by a "ping-pong" mechanism (accepting electrons from NAD (P) $\mathrm{H}$ and then reducing complexed $\mathrm{Fe}^{3+}$ ) (Figure 10B). Due to study design concerns from the Farhana et al. model and failure to identify MAP2960c, we propose that the correct iron assimilation pathway for MAP is likely the Ryndak et al. model. In addition to MAP3734c-MAP3736c, we have identified MAP3737, a PPE related gene, within the iron network (Additional file 17). Research performed by Rodriguez et al. showed that genes from the PE/PPE family are upregulated during iron limitation and repressed by IdeR in $M$. tuberculosis [99]. Structural studies by Strong et al. suggest the PPE proteins may serve as signal transduction molecules as they resemble the cytoplasmic domain of the serine chemotaxis domain (Tsr) [108]. The Tsr cytoplasmic domain functions as a multidomain protein capable of sensing extracellular signals, which are transmitted into the cell via a phosphorylation cascade 
[108]. Furthermore, we have identified upregulation of nitric oxide synthtase 2 (NOS-2) by host cells, which created a nitrosative environment that has been shown to enhance iron-scavenging programs in $M$. tuberculosis [55]. Upregulation of NOS-2 may promote MAP3734c$3736 c$ expression due to MAP3737 sensing, which would activate the iron uptake system (Figure 10A and B). The $M A P 3734 c-3736 c$ iron assimilation models (Farhana and Ryndak) argue that mycobactin is not required for iron uptake from Fe-cMyco. This is further strengthened by the growth of $M$. tuberculosis $m b t B$ mutant controls, which do not synthesize mycobactin or carboxymycobactin but have an intact irt $A B$ system, when provided with exogenous Fe-cMyco [105]. This may also explain successful MAP replication inside macrophages and mycobactin independence in some MAP laboratory strains cultured in vitro (provided inclusion of $1 \%$ ferric ammonium citrate and $\mathrm{pH} \sim 5.5$ ) despite a truncation in the EntE domain of, the first gene in the mycobactin biosynthesis gene cluster $[88,103,109-111]$. It is also important to note that in vitro cultivation of isolated MAP from feces and tissue samples require medium supplementation by mycobactin; therefore, the possibility remains that MAP3734c-3736c activity may depend upon cues provided by the host cell, such as nitric oxide, or multiple in vitro passages within the laboratory [112]. Similarly, MAP3734c-3736c may also be employed during a specific stage in infection as iron from Fe-cMyco transfer to mycobactins in the cell surface has been reported, albeit in an in vitro setting only [113]. This model contradicts the hypothesized loss of function of $m b t A$ (based on genome sequencing) described by Li et al.. However, it is important to note that the consequences of the EntE truncation in $m b t A$ have not been validated by functional studies, including those replacing the $m b t A$ gene with a completed version. Interestingly, Barclay et al. have described mycobactin independence (e.g. does not require mycobactin supplementation) and subsequent mycobactin synthesis in MAP and $M$. avium after multiple rounds of in vitro subculture [114]. Barclay et al. showed that the synthesized mycobactin was structurally different than supplemented mycobactin using high-pressure liquid chromatography [114]. The potential remains that the $m b t A$ truncation results in reduced function rather than an entire loss of function. We propose that MAP3734c-3736c and MAP3737 may play an important role during initial infection as a previous study conducted by our group reported the downregulation of this operon in intestinal tissues collected from subclinical JD positive cows [28]. The discrepancy between the two studies is likely reflective of infection stage as the MAP transcriptome from tissues were found largely to be downregulated, which is characteristic of a "hunkered-down" phase associated with subclinical/latent infection as opposed to initial infection where multiple genes are employed for pathogen establishment [115]. Creation of MAP3734c$M A P 3736 c$ deletions will be necessary to assign a definitive role to this operon and which model best represents this operon as well as determine if infection stage may impact its activity. To our knowledge, this is the first study to show $\operatorname{irtAB}(M A P 3734 c-3736 c)$ employment by MAP as well as in a co-culture model of infection. These data provide further support that $\operatorname{irt} A B$ is a functional iron assimilation system used by slow-growing mycobacteria during infection.

\section{Conclusions}

We established a primary macrophage cell culture reminiscent of macrophages found within the lamina propria. We profiled both host and MAP transcriptomes simultaneously using massively parallel ultradeep sequencing technology. Contrary to the reported literature, MAP infection inside the epithelium is a dynamic process that involves immune dysregulation (e.g. downregulation of complement and increased interferon activity) as well as mycolic acid building and DNA repair by MAP. We propose that the epithelium serves as a pathogen "boot camp" that trains MAP for efficient long-term survival within the macrophage phagosome. This epithelium "boot camp" for MAP has for the first time been shown as an interactome of initial MAP infection. We have uncovered an iron assimilation system linked to NOS-2 activity by the host, which is unrecognized in MAP research. Creation of the interactome has created previously unknown MAP pathways and identified multiple targets for potential therapeutics as well as data that can be subsequently used for hypothesis-driven research.

\section{Methods}

\section{Ethics statement}

All animal work was conducted in accordance with the recommendations in the institutional guidelines and approved animal care and use committee (IACUC) protocols at the University of Minnesota (approval number 1106A01161). All other experiments were carried out in accordance with the University of Minnesota's Institutional Biosafety Committee (IBC) approved protocol number 0806H36901.

\section{Bacterial cell culture}

A stock culture of Mycobacterium avium subsp. paratuberculosis strain K-10 (MAP K-10) was maintained in Middlebrook 7H9 medium supplemented with $1 \%$ glycerol, $10 \%$ oleic-acid-dextrose-catalase (OADC), and mycobactin J (2.0 mg/L) (Allied Monitor, Fayette, MO) at $37^{\circ} \mathrm{C}$ with shaking at $120 \mathrm{rpm}$. Prior to co-culture invasion assays, MAP K-10 was subcultured at $1 / 10$ th the original culture volume until logarithmic growth was achieved (O.D.600 $=$ 1.0, $1 \times 10^{9} \mathrm{CFU} / \mathrm{mL}$ ). 


\section{Mammalian cell culture}

Monocyte derived macrophages (MDMs) were elutriated and matured separately from three Johne's disease free dairy cows 2170 and 3210 as described. Briefly, blood was collected from the jugular vein into a chemically sterilized container containing $200 \mathrm{~mL}$ of heparin, which served as an anticoagulant. Blood was transferred into DNase/RNase free polystyrene conical tubes and centrifuged at 2, $200 \mathrm{rpm}$ for $20 \mathrm{~min}$ at room temperature (RT). Buffy coats were collected, washed in 1X Dulbecco's phosphate buffer saline (D-PBS), and layered on top of a $58 \%$ percoll gradient (Sigma-Aldrich, St. Louis, MO). The buffy coat-percoll layers were centrifuged at 3,000 rpm for $30 \mathrm{~min}$ and decelerated without brake application. Cells were removed from percoll, washed $3 \times$ in $1 \mathrm{X}$ D-PBS, and matured in Teflon flasks containing RPMI 1640 with $20 \%$ autologous serum for $4 \mathrm{~d}$ at $37^{\circ} \mathrm{C}$ in a humidified chamber containing $5 \% \mathrm{CO}_{2}$.

MAC-T cells, derived from a bovine mammary epithelial cell line, were cultured in DMEM containing 10\% fetal bovine serum at $37^{\circ} \mathrm{C}$ in a humidified chamber containing $5 \%$ $\mathrm{CO}_{2}$. Upon $90 \%$ confluence, cells were divided using TrypLE Express (Invitrogen, Carlsbad, CA) per manufacturer's instructions. MAC-T cells were utilized in this study as this cell-line is considered a surrogate for the intestinal epithelium and the source of the cell line, the mammary, is hypothesized to serve as a reservoir for MAP in vivo [23].

\section{Co-culture invasion assay}

All incubation steps involving the co-culture invasion assay occurred in a $37^{\circ} \mathrm{C}$ humidified chamber containing $5 \% \mathrm{CO}_{2}$ unless otherwise stated. MAC-T/bovine MDMs co-culture invasion assays were conducted using a described method with slight modifications [33]. In short, approximately $2.0 \times 10^{4} \mathrm{MAC}$ - T cells were seeded on the apical side of $3.0 \mu \mathrm{m}$ pore size transwell (12 well plate format) (Corning, Lowell, MA) and incubated in DMEM with $10 \% \mathrm{FBS}$ for $4 \mathrm{~d}$ at $37^{\circ} \mathrm{C}$. Once MAC-T cells were $70 \%$ confluent, bovine MDMs were seeded at $\sim 2.0 \times 10^{4}$ cells in the basolateral chamber and allowed to adhere for $2 \mathrm{~h}$ at $37^{\circ} \mathrm{C}$. Upon completion of incubation, cells were gently washed $3 \times$ using $1 \mathrm{X}$ D-PBS to remove nonadherent cells and DMEM medium containing 10\% FBS was replaced. MAC-T/bovine MDMs were incubated an additional $2 \mathrm{~d}$ to establish a link between cell types.

MAP K-10 was subcultured at 1/10th the original culture volume and incubated until an O.D.600 of 1.0 was obtained. Upon optical density measurement, MAP K-10 was pelleted at $3,000 \times \mathrm{g}$ for $10 \mathrm{~min}$, washed $3 \times$ in $1 \mathrm{X}$ D-PBS and resuspended in DMEM containing 10\% FBS such that a MOI of 10:1 was achieved. In order to ensure a single cell suspension, resuspended MAP K-10 was vortexed for $5 \mathrm{~min}$ and repeatedly drawn through a 21 gauge needle syringe. The MAP K-10 suspension was incubated in a $37^{\circ} \mathrm{C}$ water bath for $5 \mathrm{~min}$ to sediment any remaining clumps. The upper $2 / 3$ of the MAP K-10 suspension was used for the invasion assay. MAC-T cells were infected for $3 \mathrm{~h}$, washed $3 \times$ in $1 \mathrm{X}$ D-PBS and allowed to recover for $30 \mathrm{~min}$ in DMEM containing $10 \%$ FBS. MAC-T cells were further washed as before and transwells were removed from the supports and transferred to a new sterile 12 well plate. Five hundred $\mu \mathrm{L}$ of TRIzol (Invitrogen, Carlsbad, CA) was separately mixed into each transwell and well from the original plate containing bovine MDMs and incubated for $5 \mathrm{~min}$ at room temperature to ensure complete lysis. All cell lysates were collected and stored at $-80^{\circ} \mathrm{C}$ in individual RNase/DNase free $1.7 \mathrm{~mL}$ eppendorf tubes until further processing.

\section{Total RNA extraction}

Prior to RNA extraction, work surfaces and equipment were treated with RNase Away (Molecular Bioproducts, San Diego, CA). RNA was extracted from twelve samples composed of 4 uninfected host cell types (Macrophage and MAC-T under single cell type or co-cultured conditions), 4 infected host cell types (Macrophage and MAC-T under single cell type or co-cultured conditions), 2 pathogen samples from macrophages and MAC-T cells under single cell type culture, and 2 pathogen samples from co-cultured macrophages and MAC-T cells (Figure 1). All samples were collected after 30 min p.i.. Cell lysates in TRIzol were mixed with sterile RNase-free $0.1 \mathrm{~mm}$ silica zirconium beads (Biospec) and homogenized using a MagNa Lyser for $4 \mathrm{~min}$ (Roche, Indianapolis, IN). RNA was extracted following manufacturer's instructions (Invitrogen, Carlsbad, CA) and treated with Turbo DNase (Ambion, Austin, TX) at $37^{\circ} \mathrm{C}$ for $30 \mathrm{~min}$. Turbo DNase was inactivated using phenol/ chloroform extraction. RNA purity was assessed by measuring the 260/280 ratio with the Nanodrop ND-1000 (Nanodrop Products, Willimington, DE). Also, a direct PCR confirmed the absence of $\beta$-actin amplification in RNA samples. RNA samples were stored in $10 \mu \mathrm{L}$ aliquots at $-80^{\circ} \mathrm{C}$ until further processing.

\section{Enrichment of MAP RNA}

Approximately $10 \mu \mathrm{L}$ of RNA (one from each MAP treatment) was submitted to enrichment and amplification for MAP transcripts using MICROBEnrich (Ambion, Austin, TX) and MessageAmpII bacteria kit (Ambion, Austin, TX) per manufacturer's instructions. Successful elimination of host RNA was determined by the RNA 6000 LabChip kit and Agilent Bioanalyzer (Caliper Technologies Corp., Hopkinton, MA and Agilent Technologies, Santa Clara, CA).

\section{Sample processing and RNA-Seq}

Ten $\mu \mathrm{g}$ of RNA from each sample was suspended in $50 \mu \mathrm{L}$ of nuclease free water. In order to ensure RNA 
integrity and purity, all samples were quantified using the RiboGreen assay per manufacturer's instructions (Invitrogen, Carlsbad, CA) and analyzed on the Agilent Nanochip (Agilent Technologies, Santa Clara, CA). RNA samples were required to have a RNA Integrity Number (RIN) of 8 or greater to proceed with library creation. The RNA-Seq library was created using the mRNA Seq library preparation kit per manufacturer's instructions (Illumina Inc., San Diego, CA). The purified library was later validated and quantified using the Agilent High Sensitivity Chip (Agilent Technologies, Santa Clara, CA), picogreen assay (Invitrogen, Carlsbad, CA), and KAPA qPCR (KAPA Biosystems, Woburn, MA) as described by the corresponding manufacturer. The Illumina cBOT (Illumina Inc., San Diego, CA) was used for cluster generation. Briefly, the template (samples in 8-plex) was immobilized to a random oligo lawn on the flow cell surface, which was later amplified, linearized, blocked and hybridized to the sequencing primer. The clustered flow cell was then transferred and loaded into the Illumina Genome Analyzer $\mathrm{II}_{\mathrm{x}}$ (GaIIx) (Illumina Inc., San Diego, CA). Sequencing was conducted in pair-end reads. Twenty million reads (200 bp insert size) and 7.5 million reads (150 bp insert size) were recorded for each bovine and MAP samples, respectively. A Pass/Fail score was calculated for all samples using Consensus Assessment of Sequence and Variation (CASAVA) Version 1.6 software (Illumina Inc., San Diego, CA) based on reads quality score (Additional file 1 : sheets 1 and 12). Average and individual reads had Phred (passRead) scores of above 30 (Additional file 1: sheets 1 and 12 and Additional file $18 \mathrm{~A}$ and $\mathrm{C}$ ). All sequence information was converted into FASTQ files for each sample. All FASTQ files are available through NCBI SRA (http://www.ncbi.nlm.nih. gov/bioproject/218473), Project ID PRJNA218473.

\section{RNA-Seq mapping to reference genomes}

Bovine and MAP read files were analyzed in Galaxy (https://sites.google.com/a/umn.edu/galaxy-umn/home) using Tuxedo Suite Tools. The sequence quality was checked and the low quality $5^{\prime}$ end bases were trimmed. Bovine FASTQ files were mapped to the B. taurus genome (Btau 4.0) using TopHat (v2.02) with 2 mismatch setting. The differential gene expression (DGE) was analyzed using Cufflinks (Cuffdiff program) [116-118]. MAP FASTQ files were mapped to the MAP K-10 genome using Bowtie with 2 mismatch and the DGE was examined using edgeR program in BioConductor. DGE was determined by a q-value cutoff of 0.05 or p-value cutoff of 0.05 as determined by Cuffdiff and edgeR, respectively. Principal component analysis (PCA) in Expressionist using reads per kilobase of exon model per million mapped reads (RPKM) and fragments per kilobase of exon model per million mapped reads (FPKM) values was conducted in order to insure sample stratification
(Additional file 18B and D). As expected, host samples were stratified by cell type and MAP samples were separated by infected cell type (Additional file 18B and D).

\section{Host canonical pathway and functional network analyses}

Bovine transcripts and expression values identified by DGE were uploaded into Ingenuity Pathway Analysis (IPA) (Redwood City, CA) and screened for canonical pathways within the IPA library and knowledge base. The IPA library consists of pathways from the mouse, human and rat genomes; therefore, identified pathways were based on homologous genes from the bovine genome. Genes with a q-value cutoff of 0.05 were considered for pathway analysis.

Bovine transcripts and corresponding expression levels were mapped to gene objects within the IPA knowledge base. Mapped genes, called focus genes, were overlaid onto a global molecular network using information supplied by the IPA knowledge base. Focus gene networks were algorithmically generated based on connectivity. Biological function was assigned to each network based on specific focus genes identified in the IPA knowledge base. Fisher's exact test was used to determine the probability that each function assigned to a network was not due to chance alone.

\section{MAP Functional network and pathway analyses}

MAP transcripts identified by RNA-seq mapping that had a $P<0.05$ were considered for network analyses. MAP

\section{Table 6 Primers used for qT-RT-PCR}

\begin{tabular}{|c|c|}
\hline Gene and direction & Sequence $\left(5^{\prime}-3^{\prime}\right)$ \\
\hline fstl1, F & GTGTGTGTGCCTGTGGAAAC \\
\hline fstll, $R$ & TCTGATTCTITCCGTCACAGG \\
\hline$C D 46, F$ & GGTACCCTTAAACCCAGTTATAGTCC \\
\hline$C D 46, R$ & CTGGAAACCCAGACGACATT \\
\hline$B 2 M, F$ & AAGGATGGCTCGCTTCGT \\
\hline$B 2 M, R$ & GCGTCCAGTCCAGACAGC \\
\hline$B C A M, F$ & GGATCCCCCTCCTGAGTC \\
\hline$B C A M, R$ & ACTCTGGTGTCCCTTGAACC \\
\hline$D H R S I 3, F$ & CCAGACACCCCTGTACTGC \\
\hline$D H R S I 3, R$ & CGAAGTACCTCCCGCTGAG \\
\hline$B$-actin, $F$ & TCCTCCCTGGAGAAGAGCTA \\
\hline B-actin, $R$ & GTAGAGGTCCTTGCGGATGT \\
\hline$C D 274, F$ & GCGATCACCAAGTCCTGAGT \\
\hline$C D 274, R$ & GCTTTTCCTCCCTCTTTGAAC \\
\hline TNFAIP3, F & AGATGAAGGAAAAGCTCCTGAA \\
\hline TNFAIP3, $R$ & AGCCTTGAACGGGGATTT \\
\hline IFITM1, F & TCTAGGGACCGGAAGATGGT \\
\hline IFITM1, R & ACTTGGCGGTAGAGGCGTA \\
\hline
\end{tabular}


gene identification numbers were uploaded into Search Tool for the Retrieval of Interacting Genes (STRING) ver. 9.0 and examined for gene networks [119]. Gene connections were created based on direct (physical) and indirect (functional) interactions derived from genomic context, high-throughput experimentation, coexpression and knowledge reported in literature. MAP networks identified by STRING ver. 9.0 were analyzed for pathways. Pathways were established by extensive domain searches and annotated functions, which were compared to the Kyoto Encyclopedia of Genes and Genomes (KEGG) pathways and knowledge reported in the literature including information published on $M$. tuberculosis.

\section{Interactome development and functional analysis}

As previously described, DGE expression for bovine and MAP transcripts was determined by Cuffdiff and edgeR, respectively. DGE data for co-cultured conditions versus a single cell type during MAP infection (both host and pathogen transcripts) were combined. A cluster analysis was performed using the $\mathrm{k}$-means algorithm to visualize expression patterns shared between bovine and MAP transcripts. Biological processes were assigned to bovine genes that correlated with MAP transcripts using Gene Ontology identified by Database for Annotation, Visualization, and Integrated Discovery (DAVID) v6.7 (http://david.abcc. ncifcrf.gov/).

\section{Quantitative real-time PCR validation}

Quantitative real-time PCR (qT-RT-PCR) was conducted on selected host (3 upregulated, 3 downregulated, and 3 non-differentially expressed) genes (Table 6) using the Quantifast One-Step SYBR Green qT-RT-PCR kit (Qiagen, Valencia, CA). All samples were analyzed on a Roche Lightcycler 480II with corresponding software (Roche NimbleGen Inc., Madison, WI). The following cycling program was used: $50^{\circ} \mathrm{C}$ for $10 \mathrm{~min}, 95^{\circ} \mathrm{C}$ for 5 min, $95^{\circ} \mathrm{C}$ for $10 \mathrm{~s}$ and $60^{\circ} \mathrm{C}$ for $30 \mathrm{~s}$ for 40 cycles. Primers were designed using Primer 3 (http://frodo.wi.mit.edu/ primer3/). Fold change was calculated using the ${ }^{\Delta \Delta} \mathrm{CT}$ method and the house-keeping gene, $\beta$-actin, which was normalized to uninfected macrophages. Fold changes were graphed using GraphPad Prism software (GraphPad Software Inc., La Jolla, CA). Correlation coefficient $\left(\mathrm{r}^{2}\right)$ was calculated using GraphPad software. qT-RT-PCR products were examined on a $2 \%$ agarose gel. All samples were conducted in triplicate.

\section{Additional files}

Additional file 1: Sheets 1-12: Differentially expressed genes identified by RNA-seq. Total read counts. S1 is uninfected MAC-T cells alone, S2 is uninfected macrophages alone, S3 is MAP infected MAC-T cells alone, S4 is MAP infected macrophages alone, S5 is co-cultured MAC-T cells, $\mathrm{S} 6$ is co-cultured macrophages, S7 is MAP infected co-cultured MAC-T cells, and S8 is MAP infected co-cultured macrophages. Fold changes are calculated based on infection status and culture comparisons. Genes shown have a $P<0.05$.

Additional file 2: Downregulation of protein synthesis and cell cycle network in uninfected co-cultured MAC-T cells. Downregulated genes are shown in green. Upregulated genes are shown in red. Color intensity reflects degree of downregulation/upregulation. Solid lines represent direct relationships. Dotted lines represent indirect relationships. Genes shown have a $P<0.05$

Additional file 3: Downregulation of assembly and organization, cellular function and maintenance, nucleic acid metabolism network in uninfected co-cultured MAC-T cells compared to uninfected MAC-T cells cultured alone. Downregulated genes are shown in green. Upregulated genes are shown in red. Color intensity reflects degree of downregulation/upregulation. Solid lines represent direct relationships. Dotted lines represent indirect relationships. Genes shown have a $\mathrm{P}<0.05$

Additional file 4: Downregulation of network involved in cancer, dermatological diseases and conditions and lymphoid tissue structure and development in uninfected co-cultured MAC-T cells compared to uninfected MAC-T cells cultured alone. Downregulated genes are shown in green. Color intensity reflects degree of downregulation. Solid lines represent direct relationships. Dotted lines represent indirect relationships. Genes shown have a $\mathrm{P}<0.05$.

Additional file 5: Downregulation of cell cycle, cell morphology, and cellular assembly and organization network in uninfected co-cultured MAC-T cells compared to uninfected MAC-T cells cultured alone. Downregulated genes are shown in green. Color intensity reflects degree of downregulation. Solid lines represent direct relationships. Dotted lines represent indirect relationships. Genes shown have a $\mathrm{P}<0.05$.

Additional file 6: Downregulation of inflammatory disease network in uninfected co-cultured macrophages compared to uninfected macrophages cultured alone. The majority of differentially expressed genes identified in the inflammatory disease network were downregulated. Downregulated genes are shown in green. Upregulated genes are shown in red. Color intensity reflects degree of downregulation/upregulation. Solid lines represent direct relationships. Dotted lines represent indirect relationships. Genes shown have a $\mathrm{P}<0.05$.

Additional file 7: Downregulation of molecular transport network in uninfected co-cultured macrophages compared to uninfected macrophages cultured alone. The majority of differentially expressed genes identified in the molecular transport network were downregulated. Downregulated genes are shown in green. Upregulated genes are shown in red. Color intensity reflects degree of downregulation/upregulation. Solid lines represent direct relationships. Dotted lines represent indirect relationships. Genes shown have a $\mathrm{P}<0.05$.

Additional file 8: Downregulation of infectious disease network in uninfected co-cultured macrophages compared to uninfected macrophages cultured alone. The majority of differentially expressed genes identified in the infectious disease network were downregulated. Downregulated genes are shown in green. Upregulated genes are shown in red. Color intensity reflects degree of downregulation/upregulation. Solid lines represent direct relationships. Dotted lines represent indirect relationships. Genes shown have a $P<0.05$

Additional file 9: Upregulation of cellular growth and proliferation network in response to MAP infection in co-cultured MAC-T cells compared to infection in MAC-T cells alone. The majority of differentially expressed genes were upregulated. Downregulated genes are shown in green. Upregulated genes are shown in red. Color intensity reflects degree of downregulation/upregulation. Solid lines represent direct relationships. Dotted lines represent indirect relationships. Genes shown have a $\mathrm{P}<0.05$

Additional file 10: Upregulation of DNA replication, recombination and repair in response to MAP infection in co-cultured MAC-T cells 
compared to infection in MAC-T cells alone. All differentially expressed genes found in this network were upregulated. Upregulated genes are shown in red. Color intensity reflects degree of downregulation/upregulation. Solid lines represent direct relationships. Dotted lines represent indirect relationships. Genes shown have a $\mathrm{P}<0.05$.

Additional file 11: Downregulation of cell death network in response to MAP infection in co-cultured macrophages vs. infected macrophages alone. Downregulated genes are shown in green Upregulated genes are shown in red. Color intensity reflects degree of downregulation/upregulation. Solid lines represent direct relationships. Dotted lines represent indirect relationships. Genes shown have a $\mathrm{P}<0.05$.

Additional file 12: Upregulation of cell to cell communication and signaling in response to Map infection in co-cultured macrophages vs. infected macrophages alone. Downregulated genes are shown in green. Upregulated genes are shown in red. Color intensity reflects degree of downregulation/upregulation. Solid lines represent direct relationships. Dotted lines represent indirect relationships. Genes shown have a $\mathrm{P}<0.05$.

Additional file 13: Network Analysis of differentially expressed MAP genes during MAC-T cells infection vs. macrophage infection. Genes shown have a $P<0.05$. STRING software depicts the following relationships by colored lines: neighborhood $=$ green, gene fusion $=$ red, co-occurrence $=$ blue, experiments $=$ pink, databases $=$ turquoise textmining $=$ yellow and homology $=$ periwinkle

Additional file 14: Network Analysis of differentially expressed MAP genes during MAC-T cell infection cultured alone vs. MAC-T cells under co-cultured conditions. Genes shown have a $\mathrm{P}<0.05$. STRING software depicts the following relationships by colored lines: neighborhood $=$ green, gene fusion $=$ red, co-occurrence $=$ blue, experiments $=$ pink, databases $=$ turquoise, textmining $=$ yellow and homology = periwinkle

Additional file 15: Network Analysis of differentially expressed MAP genes in co-cultured MAC-T cells vs. co-cultured macrophages. Genes shown have a $P<0.05$. STRING software depicts the following relationships by colored lines: neighborhood = green, gene fusion $=$ red, co-occurrence $=$ blue, experiments $=$ pink, databases $=$ turquoise textmining = yellow and homology = periwinkle.

Additional file 16: K-clustering analysis. K-clustering analysis identified 81 host genes that shared a similar regulation pattern profile with 77 MAP genes. b3 = MAP genes in MAC-T cells alone, b7 = MAP genes in co-cultured MAC-T cells, b4 = MAP genes in macrophages alone, b8 = MAP genes in co-cultured macrophages, $\mathrm{m} 3=$ MAP genes in MAC-T cells alone, $\mathrm{m} 7=$ MAP genes in co-cultured MAC-T cells, $\mathrm{m} 4=$ MAP genes in macrophages alone, and $\mathrm{m} 8=$ MAP genes in co-cultured macrophages .

Additional file 17: Interactome network analysis. Genes shown have a $\mathrm{P}<0.05$. STRING software depicts the following relationships by colored lines: neighborhood $=$ green, gene fusion $=$ red, co-occurrence $=$ blue, experiments $=$ pink, databases $=$ turquoise, textmining $=$ yellow and homology = periwinkle.

Additional file 18: RNA-seq quality control. Bovine and MAP profiles were analyzed in Galaxy using the Tuxedo Suite Tools. A) Average and individual reads for bovine transcripts had a Phred score above 30. B) Principal component analysis (PCA) of bovine transcripts. All transcripts stratified according to cell type. C) Average and individual reads for MAP transcripts had a Phred score above 30. D) PCA shows all MAP transcripts stratified according to infected cell type.

\section{Competing interests}

The authors claim no competing interests.

\section{Authors' contributions}

EAL performed experiments. EAL, WWX, and SS analyzed and interpreted data. EAL and SS wrote the paper. SS provided financial support. All authors read and approved the final manuscript.

\section{Acknowledgements}

We thank Dr. Luiz E. Bermudez (Oregon State University) for his generous gift of MAC-T cells. We thank Dr. Scott M. O'Grady (University of Minnesota) for technical advice and expertise on co-culture development. Special recognition is given to Dr. John P. Bannantine (National Animal Disease Center, USDA-ARS) for useful discussions in experimental setup. We acknowledge the services provided by the Biomedical Genomics Center, the Minnesota Supercomputing Institute, and the Bovine Blood Collection at the University of Minnesota. We appreciate the assistance of Derek Lieffring during blood collections. We thank the University of Minnesota's College of Veterinary Medicine Agriculture Research Station grant (1802-11646-AES0062027) awarded to S.S. for support of this study.

\section{Author details}

${ }^{1}$ Department of Veterinary Population Medicine, College of Veterinary Medicine, University of Minnesota, 1971 Commonwealth Avenue, Saint Paul, MN 55108, USA. 'Department of Veterinary Biomedical Sciences, University of Minnesota, Saint Paul, MN 55108, USA. ${ }^{3}$ Minnesota Supercomputing Institute, University of Minnesota, Saint Paul, MN 55108, USA

Received: 13 April 2013 Accepted: 2 October 2013

Published: 10 October 2013

\section{References}

1. Sansonetti P: Host-Pathogen interactions: the seduction of molecular cross talk. Gut 2002, 50(3):1112-1118.

2. Huynh KK, Joshi SA, Brown EJ: A delicate dance: host response to mycobacteria. Curr Opin Immunol 2011, 23:464-472.

3. Finlay B, Cossart P: Exploitation of mammalina host cell functions by bacterial pathogens. Science 1997, 276:718-725.

4. Etienne-Mesmin L, Chassaing B, Sauvanet P, Denizot J, Blanquet-Diot S, Darfeuille-Michaud A, Pradel N, Livrelli V: Interactions with $\mathrm{M}$ cells and macrophages as key steps in the pathogenesis of enterohemorragic Escherichia coli infections. PLoS One 2011, 6(8):1-13.

5. Secott TE, Lin TL, Wu CC: Fibronectin attachment protein homologue mediates fibronectin binding by Mycobacterium avium subsp. paratuberculosis. Infect Immun 2001, 69(4):2075-2082.

6. Secott TE, Lin TL, Wu CC: Fibronectin attachment protein is necessary for efficient attachment and invasion of epithelial cells by Mycobacterium avium subsp. paratuberculosis. Infect Immun 2002, 70(5):2670-2675.

7. Ashida H, Ogawa M, Kim M, Suzuki S, Sanada T, Punginelli C, Mimuro H Sasakawa C: Shigella deploy multiple countermeasures against host innate immune responses. Curr Opin Microbiol 2011, 14(1):16-23.

8. Derache C, Esnault E, Bonsergent C, Le Vern Y, Quere P, Lalmanach AC: Differential modulation of beta-defensin gene expression by Salmonella Enteritidis in intestinal epithelial cells from resistant and susceptible chicken inbred lines. Dev Comp Immunol 2009, 33(9):959-966.

9. Kohler H, Sakaguchi T, Hurley BP, Kase BA, Reinecker HC, McCormick BA Salmonella enterica serovar Typhimurium regulates intercellular junction proteins and facilitates transepithelial neutrophil and bacterial passage. Am J Physiol Gastrointest Liver Physiol 2007, 293(1):G178-G187.

10. Sakaguchi T, Kohler H, Gu X, McCormick BA, Reinecker HC: Shigella flexneri regulates tight junction-associated proteins in human intestinal epithelial cells. Cell Microbiol 2002, 4(6):367-381.

11. Srikanth CV, Wall DM, Maldonado-Contreras A, Shi HN, Zhou D, Demma Z, Mumy KL, McCormick BA: Salmonella pathogenesis and processing of secreted effectors by caspase-3. Science 2010, 330(6002):390-393.

12. Ott SL, Wells SJ, Wagner BA: Herd-level economic losses associated with Johne's disease on US dairy operations. Prev Vet Med 1999, 40(3-4):179-192

13. Secott TE, Lin TL, Wu CC: Mycobacterium avium subsp. paratuberculosis fibronectin attachment protein facilitates M-cell targeting and invasion through a fibronectin bridge with host integrins. Infect Immun 2004 72(7):3724-3732.

14. Chacon O, Bermudez LE, Barletta RG: Johne's disease, inflammatory bowel disease, and Mycobacterium paratuberculosis. Annu Rev Microbiol 2004, 58:329-363

15. Clarke CJ: The pathology and pathogenesis of paratuberculosis in ruminants and other species. J Comp Pathol 1997, 116(3):217-261.

16. Murphy JT, Sommer S, Kabara EA, Verman N, Kuelbs MA, Saama P, Halgren R, Coussens PM: Gene expression profiling of monocyte-derived macrophages following infection with Mycobacterium avium subspecies avium and Mycobacterium avium subspecies paratuberculosis. Physiol Genomics 2006 28(1):67-75. 
17. Sigurdardottir OG, Bakke McKellep AM, Djonne B, Evensen O: Mycobacterium avium subsp. paratuberculosis enters the small intestinal mucosa of goat kids in areas with and without Peyer's patches as demonstrated with the everted sleeve method. Comp Immunol Microbiol Infect Dis 2005, 28(3):223-230.

18. Coussens PM, Colvin CJ, Wiersma K, Abouzied A, Sipkovsky S: Gene expression profiling of peripheral blood mononuclear cells from cattle infected with Mycobacterium paratuberculosis. Infect Immun 2002, 70(10):5494-5502.

19. Souza CD, Evanson OA, Weiss DJ: Role of the mitogen-activated protein kinase pathway in the differential response of bovine monocytes to Mycobacterium avium subsp. paratuberculosis and Mycobacterium avium subsp. avium. Microbes Infect 2007, 9(14-15):1545-1552.

20. Weiss DJ, Evanson OA, de Souza C, Abrahamsen MS: A critical role of interleukin-10 in the response of bovine macrophages to infection by Mycobacterium avium subsp paratuberculosis. Am J Vet Res 2005, 66(4):721-726.

21. Zhu X, Tu ZJ, Coussens PM, Kapur V, Janagama H, Naser S, Sreevatsan S: Transcriptional analysis of diverse strains Mycobacterium avium subspecies paratuberculosis in primary bovine monocyte derived macrophages. Microbes Infect 2008, 10(12-13):1274-1282.

22. Weiss DJ, Evanson OA, Moritz A, Deng MQ, Abrahamsen MS: Differential responses of bovine macrophages to Mycobacterium avium subsp. paratuberculosis and Mycobacterium avium subsp. avium. Infect Immun 2002, 70(10):5556-5561.

23. Patel D, Danelishvili L, Yamazaki Y, Alonso M, Paustian ML, Bannantine JP, MeunierGoddik L, Bermudez LE: The ability of Mycobacterium avium subsp. paratuberculosis to enter bovine epithelial cells is influenced by preexposure to a hyperosmolar environment and intracellular passage in bovine mammary epithelial cells. Infect Immun 2006, 74(5):2849-2855.

24. Kim SY, Sohn H, Choi GE, Cho SN, Oh T, Kim HJ, Whang J, Kim JS, Byun EH, Kim WS, et al: Conversion of Mycobacterium smegmatis to a pathogenic phenotype via passage of epithelial cells during macrophage infection. Med Microbiol Immun 2011, 200(3):177-191.

25. Alonso Hearn M, Patel D, Danelishvili L, Meunier Goddik L, Bermudez LE: he Mycobacterium avium subsp. paratuberculosis MAP3464 gene encodes an oxidoreductase involved in invasion of bovine epithelial cells through the activation of host cell Cdc42. Infect Immun 2008, 76(1):170-178.

26. Nobes $C D$, Hall A: Rho, rac, and cdc42 GTPases regulate the assembly of multimolecular focal complexes associated with actin stress fibers, lamellipodia, and filopodia. Cell 1995, 81(1):53-62.

27. Zamudio-Meza H, Castillo-Alvarez A, Gonzalez-Bonilla C, Meza I: Cross-talk between Rac1 and Cdc42 GTPases regulates formation of filopodia required for dengue virus type- 2 entry into HMEC- 1 cells. J Gen Virol 2009, 90(Pt 12):2902-2911.

28. Janagama HK, Lamont EA, George S, Bannantine JP, Xu WW, Tu ZJ, Wells SJ, Schefers J, Sreevatsan S: Primary transcriptomes of Mycobacterium avium subsp. paratuberculosis reveal proprietary pathways in tissue and macrophages. BMC Genomics 2010, 11:561.

29. Sagaert X, Tousseyn T, De Hertogh G, Geboes K: Macrophage-related diseases of the gut: a pathologist's perspective. Virchows Arch 2012, 460(6):555-567.

30. Tyrer PC, Bean EG, Foxwell AR, Pavil P: Effects of bacterial products on enterocyte-macrophage interactions in vitro. Biochem Biophys Res Commun 2011, 413:336-341.

31. Smythies LE, Sellers M, Clements RH, Mosteller-Barnum M, Meng G, Benjamin WH, Orenstein JM, Smith PD: Human intestinal macrophages display profound inflammatory anergy despite avid phagocytic and bacteriocidal activity. J Clin Investig 2005, 115(1):66-75.

32. Walker WAaS IR: TLRs in the Gut. Am J Pysiol Gastrointest Liver Physio/ 2007 292:G6-G10.

33. Lamont EA, OGrady SM, Davis WC, Eckstein T, Sreevatsan S: Infection with Mycobacterium avium subsp. paratuberculosis results in rapid IL-1 $\beta$ release and macrophage transepithelial migration. Infect Immun 2012 , 80(9):3225-3235

34. Shea PR, Virtaneva K, Kupko JJ III, Porcella SF, Barry WT, Wright FA, Kobayashi SD, Carmody A, Ireland RM, Sturdevant DE, Ricklefs SM, Babar I, Johnson CA, Graham MR, Gardner DJ, Bailey JR, Parnell MJ, DeLeo FR, Musser JM: Interactome analysis of longitudinal pharyngeal infection of cynomolgus macaques by group A Streptococcus. Proc Natl Acad Sci USA 2010, 107(10):4693-4698.

35. Liu J, Kern JA: Neuregulin-1 activates the JAK-STAT pathway and regulates lung epithelial cell proliferation. Am J Respir Cell Mol Biol 2002, 27:306-313.
36. Chand HS, Harris JF, Mebratu Y, Chen Y, Wright PS, Randell SH, Tesfaigzi Y: Intracellular insulin-like growth factor- 1 induces $\mathrm{BCl}-2$ expression in airway epithelial cells. J Immunol 2012, 188(9):4581-4590.

37. Sun R, Zhang Q, Guo L, Chen MY, Sun Y, Cao B, Sun J: HGF stimulates proliferation through the HGF/c-Met pathway in nasopharyngeal carcinoma cells. Oncol Lett 2012, 3(5):1124-1128.

38. Harada A, Sekido N, Akahoshi T, Wada T, Mukaida N, Mutsushima K: Essential involvement of interleukin-8 (IL-8) in acute inflammation. J Leuko Biol 1994, 56(5):559-564.

39. Li B, Dong C, Wang G, Zheng H, Wang X, Bai C: Pulmonary epithelial CCR3 promotes LPS-induced lung inflammation by mediating release of IL-8. J Cell Physiol 2011, 226(9):2398-23405.

40. Mowat AM, Bain CC: Mucosal macrophages in intestinal homeostasis and inflammation. J Innat Immun 2011, 3(6):550-564.

41. Velasco-Velazquez MA, Barrera D, Gonzalez AA, Rosales C: Agramonte-H. J: Macrophage-Mycobacterium tuberculosis interactions: role of complement receptor 3. Microb Pathog 2003, 35(3):125-131.

42. Stokes RW, Haidl ID, Jefferies WA, Speert DP: Mycobacteria-macrophage interactions. Macrophage phenotype determines the nonopsonic binding of Mycobacterium tuberculosis to murine macrophages. $\mathrm{J}$ Immunol 1993, 151(12):7067-7076.

43. Sendide K, Reiner NE, Lee JS, Bourgoin S, Talal A, Hmama Z: Cross-talk between CD14 and complement receptor 3 promotes phagocytosis of mycobacteria: regulation by phosphatidylinositol 3-kinase and cytohesin-1. J Immunol 2005, 174(7):4210-4219.

44. Dugan JW, Albor A, David L, Fowlkes J, Blackledge MT, Martin TM, Planck SR, Rosenzweig HL, Rosenbaum JT, Davey MP: Nucleotide oligomerization domain-2 interacts with 2'5-oligoadenylate synthetase type 2 and enhances RNase-L function in THP-1 cells. Mol Immunol 2009, 47:560-566.

45. Newport MJ, Huxley CM, Huston S, Hawrylowicz CM, Oostra BA, Williamson R,

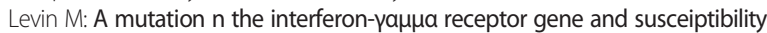
to mycobacterial infection. N Engl J Med 1996, 335:1941-1949.

46. Cooper AM, Dalton DK, Stewart TA, Griffin JP, Russell DG, Orme IM: Disseminated tuberculosis in interferon gamma gene-disrupted mice. J Exp Med 1993, 178(6):2243-2247

47. Li XL, Ezelle HJ, Kang TJ, Zhang I, Shirey KA, Harro J, Hasday JD, Mohapatra SK, Crastra OR, Vogel SN, et al: An essential role for the antibrial endoribonuclease, RNase-L, in antibacterial immunity. PNAS 2008, 105:20816-20821.

48. Sabbah A, Chang TH, Harnack R, Frolich V, Tominaga K, Dube PH, Ziang Y, Bose S: Activation of innate immune antiviral responses by Nod2. Nat Immunol 2009, 10(10):1073-1080.

49. Sampaio EP, Bax HI, Hsu AP, Kristosturyan E, Pechacek J, Chandrasekaran P, Paulson ML, Dias DL, Spalding C, Uzel G: A novel STAT1 mutation associated with disseminated mycobacterial disease. J Clin Immunol 2012, 32(4):681-689.

50. Korf H, Beken SV, Romano M, Steffensen KR, Stijlemans B, Gustafsson J, Grooten J, Huygen K: Liver X receptors contribute to the protective immune response against Mycobacterium tuberculosis in mice. J Clin Invest 2009, 119(6):1626-1637.

51. Titgemeyer F, Amon J, Parche S, Mahfoud M, Bail J, Schlicht M, Rehm N, Hillmann D, Stephan J, Walter B, et al: A genomic view of sugar transport in Mycobacterium smegmaits and Mycobacterium tuberculosis. J bacteriol 2007, 189(16):5903-5915.

52. Edson NL: The intermediary metabolism of the mycobacteria. Bacteriol Rev 1951, 15:147-182.

53. Borich SM, Murray A, Gormley E: Genomic arrangement of a putative operon involved in maltose transport in the Mycobacterium tuberculosis complex and Mycobacterium leprae. Microbios 2000, 102:7-15.

54. Braibant $M$, Gilot $P$, Content J: The ATP binding cassette $(A B C)$ transport systems of Mycobacterium tuberculosis. FEMS Microbiol Rev 2000, 24:449-467

55. Schnappinger D, Ehrt S, Voskull MI, Liu Y, Mangan JA, Monahan IM, Dolganov G, Efron B, Butcher PD, Nathan C, et al: Transcriptional adaptation of Mycobacterium tuberculosis within macrophages: insights into the phagosomal environment. J Exp Med 2003, 198(5):693-704.

56. Kendall SL, Burgess P, Balhana R, Withers M, ten Bokum A, Lott JS, Gao C, Uhia-Castro I, Stoker NG: Cholesterol utilization in mycobacteria is controlled by tow TetR-type transcriptional regulators: kstR and kstR2. Microbiology 2010, 156:1362-1371. 
57. Rengarajan J, Bloom BR, Rubin EJ: Genome-wide requirements for Mycobacterium tuberculosis adaptation and survival in macrophages. PNAS 2005, 102(3):8327-8332.

58. Kalscheuer R, Weinrick B, Veeraraghavan U, Besra GS, Jacobs WR: Trehaloserecycling $A B C$ transporter LpqY-SugA-SugB-SugC is essential for virulence of Mycobacterium tuberculosis. PNAS 2010, 107(50):21761-21766.

59. Williams KJ, Boshoff HI, Krishnan N, Gonzales J, Schnappinger D, Robertson BD: The Mycobacterium tuberculosis $\beta$-oxidation genes echA5 and fadB3 are dispensable for growth in vitro and in vivo. Tuberculosis (Edinb) 2011, 91(6-3):549-555.

60. Wheeler PR: Analyzing lipid metabolism: activation and beta-oxidation of fatty acids. Methods Mol Biol 2009, 465:47-59.

61. Pino C, Olmo-Mira F, Cabello P, Martinez-Luque M, Castillo F, Roldan MD, Moreno-Vivian C: The assimilatory nitrate reduction system of the phototrophic bacterium Rhodobacter capsulatus E1F1. Biochem Soc Trans 2006, 34(Pt 1):127-129

62. Dullaghan EM, Brooks PC, Davis EO: The role of multiple SOS boxes upstream of the Mycobacterium tuberculosis lexA gene-identification fo a novel DNA-damage-inducible gene. Microbiology 2002, 148:3609-3615.

63. Heltzel JM, Maul RW, Ponticelli SKS, Sutton MD: A model for DNA polymerase swithcing involving a single cleft and the rim of the sliding clamp. PNAS 2009, 106(31):12664-12669.

64. Erill I, Campoy S, Mazon G, Barbe J: Dispersal and regulation of an adaptive mutagenesis cassette in the bacteria domain. Nucleic Acids Res 2006, 34(1):66-77.

65. Pages V, Fuchs RPP: How DNA lesions are turned into mutations within cells? Oncogene 2002, 21:8957-8966.

66. Warner DF, Ndwandwe DE, Abrahams G, Kana BD, Machowski EE, Venclovas C, Mizrahi V: Essential roles for imuA'-and imuB-encoded accessory factors in DnaE2-dependent mutagenesis in Mycobacterium tuberculosis. PNAS 2010, 107(29):13093-13098.

67. Prakash S, Johnson RE, Prakash L: Eukrayotic tanslesion syntheis DNA polymerases: specificity of structure and function. Annu Rev Biochem 2005, 74:317-353.

68. Bianchetti CM, Blouin GC, Bitto E, Olson JS, Phillips GN Jr: The structure and $\mathrm{NO}$ binding properties of the nitrophorin-like heme-binding protein from Arabidopsis thaliana gene locus At1g79260.1. Proteins 2010, 78(4):917-931.

69. Perry ACF, Bhriain NN, Brown NL, Rouch DA: Molecular characterization of the gor gene encoding glutathione reductase from Pseudomonas aeruginosa: determinants of substrate specificity among pyridine nucleotide-disulphide oxidoreductases. Mol Microbiol 1991, 5(1):163-171.

70. Burian J, Ramon-Garcia S, Sweet G, Gomez-Velasco A, Av-Gay Y, Thompson C: The Mycobacterial transcriptional regulator whiB7 gene links redox homeostsis and intrinsic antibiotic resistance. J Biol Chem 2012, 287(1):299-310

71. Alam MD, Garg SK, Agrawal P: Studies on structural and functional divergence among seven WhiB proteins of Mycobacterium tuberculosis H37Rv. FEBS J 2009, 276:76-93.

72. Zheng $F$, Long $Q$, Xie J: The function and regulatory network of WhiB and WhiB-like protein from comparative genomics and systems biology perspectives. Cell Biochem Biophys 2012, 63:103-108.

73. Morris RP, Nguyen L, Gatfield J, Visconti K, Nguyen K, Schnappinger D, Ehrt S, Liu Y, Heifets L, Pieters J, et al: Ancestral antibiotic resistance in Mycobacterium tuberculosis. PNAS 2005, 102(34):12200-12205.

74. Chauhan A, Lofton H, Maloney E, Moore J, Fol M, Madiraju MWS, Rajagopalan M: Interference of Mycobacterum tuberculosis cell division by Rv2719c, a cell wall hydrolase. Mol Microbio/ 2006, 62(1):132-147.

75. Buist G, Steen A, Kok J, Kuipers OP: LysM, a widely distributed protein motif for binding to (peptido)glycans. Mol Microbiol 2008, 68(4):838-847

76. de Jonge R, Thomma BPHJ: Fungal LysM effectors: extinguishers of host immunity? Trends Microbiol 2009, 17(4):151-157.

77. Steen A, Buist G, Horburgh GJ, Venema G, Kuipers OP, Foster SJ, Kok J. AcmA of Lactococcus lactis is an N-acetylglucosaminidase with an optimal number of LysM domains for proper functioning. FEBS J 2005 272:2854-2868.

78. Casali N, Riley LW: A phylogenomic analysis of the Actinomycetales mce operons. BMC Genomics 2007, 8:60

79. Casali N, White AM, Riley LW: Regulation of the Mycobacterium tuberculosis mce1 operon. J Bacterio/ 2006, 188(2):441-449.
80. Kumar A, Bose M, Brahmachari V: Analysis of expression profile of mammalian cell entry (mce) operons of Mycobacterium tuberculosis. Infect Immun 2003, 71(10):6083-6087.

81. Stavrum R, Stavrum A, Valvatne H, Riley LW, Ulvestad E, Jonassen I, Abmus J, Doherty TM, Grewal HMS: Modulation of transcriptional and inflammatory responses in murine macrophages by the Mycobacterium tuberculosis mammalian cell entry (Mce) 1 complex. PLoS One 2011, 6:10.

82. Xu G, Li Y, Yang J, Zhou X, Yin X, Liu M, Zhao D: Effect of recombinant mce4a protein of Mycobacterium bovis on expression of TNF-alpha, iNOS, IL-6, and IL-12 bovine alveolar macrophages. Mol Cell Biochem 2007, 302:1-7.

83. Zhang F, Xie J: Mammalian cell entry gene gamily of Mycobacterium tuberculosis. Mol Cell Biochem 2011, 352(1-2):1-10.

84. de la Paz Santangelo M, Klepp L, Nunez-Garcia J, Blanco FC, Soria M, Garcia-Pelayo MC, Bianco MV, Cataldi AA, Golby P, Jackson M, et al: Mce3R, a TetR-type transcriptional repressor, controls the expression of a regulon involved in lipid metabolism in Mycobacterium tuberculosis. Microbiology 2009, 155(Pt 7):2245-2255

85. Mitra D, Saha B, Das D, Wiker HG, Das AK: Correlating sequential homology of Mce1A, Mce2A, Mce3A and Mce4A with their possible functions in mammalian cell entry of Mycobacterium tuberculosis performing homology modeling. Tuberculosis (Edinb) 2005, 85(5-6):337-345.

86. Rowe JL, Starnes GL, Chivers PT: Complex transcriptional control links NikABCDE-dependent nickel transport with hydrogenase expression in Escherichia coli. J bacterio/ 2005, 187(8):6137-6323.

87. Campbell DR, Chapman KE, Waldron KJ, Tottey S, Kendall S, Cavallaro G, Andreini C, Hinds J, Stoker NG, Robinson NJ, et al: Mycobacterial cells have dual nickel-cobalt sensors: sequence relations and metal sites of metal responsive repressors are not congruent. J Biol Chem 2007 282(44):32298-32310.

88. Li L, Bannantine JP, Zhang Q, Amosin A, May BJ, Alt D, Banerji N, Kanjilal S, Kapur $\mathrm{V}$ : The complete genome sequence of Mycobacterium avium subspecies paratuberculosis. PNAS 2005, 102(35):12344-12349.

89. Wang D, Calla B, Vimolmangkang S, Wu X, Korban SS, Huber SC, Clough SJ, Zhao Y: The orphan gene ybjN conveys pleiotropic effects on multicellular behavior and survival of Escherichia coli. PLoS One 2011, 6:9.

90. Chen X, Shen D, Zhou B: Analysis of the temperature-sensitive mutation of Escherichia coli pantothenate kinase reveals $\mathrm{YbjN}$ as a possible protein stabilizer. Biochem Biophys Res Commun 2006, 345(2):834-842.

91. Taylor GK, Stoddard BL: Structural, functional and evolutionary relationships between homing endonucleases and proteins from their host organisms. Nucleic Acids Res 2012, 40(12):5189-5200.

92. Stephanou NC, Gao F, Bongiorno P, Ehrt S, Schnappinger D, Shurman S, Glickman MS: Mycobacterial nonhomologous end joining mediates mutagenic repair of chromosomal double-strand DNA breaks. J bacteriol 2007, 189(14):5237-5246.

93. Sundin GW, Weigand MR: The microbiology of mutability. FEMS Microbiol Lett 2007, 277:11-20.

94. Gawel D, Seed PC: Urinary tract infection drives genome instability in uropathogenic Escherichia coli and necessitates translesion synthesis DNA polymerase IV for virulence. Virulence 2011, 2(3):222-232.

95. Nohmi T: Environmental stress and lesion-bypass DNA polymerases. Annu Rev Microbiol 2006, 60:231-253.

96. Rodriguez GM, Smith I: Mechanimsms of iron regulation in mycobacteria: role in physiology and virulence. Mol Microbiol 2003, 47(6):1485-1494.

97. Banerjee S, Farhana A, Ehtesham NZ, Hasnain SE: Iron acquisition, assimilation and regulation in mycobacteria. Infect Genet Evol 2011 11:825-838.

98. De Voss JJ, Rutter K, Schroeder BC, Barry CE 3rd: Iron acquisiton and metabolism by mycobacteria. J bacteriol 1999, 181(15):4443-4451.

99. Rodriguez GM, Voskull MI, Gold B, Schoolnik GK, Smith I: ideR, an essential gene in Mycobacterium tuberculosis: role of IdeR in iron-dependent gene expression, iron metabolism, and oxidative stress response. Infect Immun 2002, 70(7):3371-3381.

100. Janagama HK, Senthilkumar TM, Bannantine JP, Rodriguez GM, Smith I, Paustian ML, McGarvey JA, Sreevatsan S: Identification and functional characterization of the iron-dependent regulator (IdeR) of Mycobacterium avium subsp. paratuberculosis. Microbiology 2009, 155(Pt 11):3683-3690.

101. Ratledge C: Iron, mycobacteria and tuberculosis. Tuberculosis (Edinb) 2004, 84(1-2):110-130 
102. Snow GA: Mycobactins: iron-chelating growth factors from mycobacteria. Bacteriol Rev 1970, 34(2):99-125.

103. Moolji J: Transposon mutagenesis of Mycobacterium avium subsp. paratuberculosis to investigate potential pathogenicity islands. Montreal: McGill University; 2010.

104. Saier MH Jr, Tseng T-T: Evolutionary origins of transmembrane transport systems, Volume 58. London: Cambridge University Press; 1999.

105. Rodriguez GM, Smith I: Identification of an $A B C$ transporter required for iron acquisition and virulence in Mycobacterium tuberculosis. $J$ bacteriol 2006, 188(2):424-430.

106. Farhana A, Kumar S, Rathore SS, Gosh PC, Ehtesham NZ, Tyagi AK, Hasnain SE: Mechanistic insights into a novel exporter-importer system of Mycobacterium tuberculosis unravel its role in trafficking of iron. PLoS One 2008, 3(5):1-16.

107. Ryndak MR, Wang S, Smith I, Rodriguez GM: THe Mycobacterium tuberculosis high-affinity iron importer, IrtA, contains an FAD-binding domain. J bacteriol 2010, 192(3):861-869.

108. Strong M, Sawaya MR, Wang S, Phillips M, Cascio D, Eisenberg D: Toward the structural genomics of complexes: crystal strucuture of a PE/PPE protein complex from Mycobacterium tuberculosis. PNAS 2006, 103(21):8060-8065.

109. Merkal RS, Curran BJ: Growth and metabolic characteristics of Mycobacterium paratuberculosis. App/ Microbiol 1974, 28(2):276-279.

110. Morrison NE: Circumvention of the mycobactin requirment of Mycobacterium paratuberculosis. J bacteriol 1965, 89(3):762-767.

111. Lambrecht RS, Collins MT: Inability to detect mycobactin in Mycobacteria infected tissues suggests an alternative iron acquisition mechanims by Mycobacteria in vivo. Microb Pathog 1993, 14:229-238.

112. Lambrecht RS, Collins MT: Mycobacterium paratuberculosis. Factors that influence mycobactin dependence. Diagn Mlcrobiol Infect Dis 1992, 15(3):239-246.

113. Gobin J, Horwitz MA: Exochelins of Mycobacterium tuberculosis remove iron from human iron-binding proteins and donate iron to mycobactins in the M. tuberculosis cell wall. J Exp Med 1996, 183(4):1527-1532.

114. Barclay R, Ewing DF, Ratledge C: Isolation, identification, and structural analysis of the mycobactins of Mycobacterium avium, Mycobacterium intracellulare, Mycobacterium scrofulaceum, and Mycobacterium paratuberculosis. J Bacterio/ 1985, 164(2):896-903.

115. Goldberg DE, Siliciano RF, Jacobs WR: Outwitting evolution: fighting drug-resistant TB, malaria, and HIV. Cell 2012, 148(6):1271-1283.

116. Trapnell C, Pachter L, Salzberg SL: TopHat: discovering splice junctions with RNA-Seq. Bioinformatics 2009, 25(9):1105-1111.

117. Trapnell C, Roberts A, Goff L, Pertea G, Kim D, Kelley DR, Pimentel H, Salzberg SL, Rinn JL, Pachter L: Differential gene and transcript expression analysis of RNA-seq experiments with TopHat and Cufflinks. Nat Protoc 2012, 7(3):562-578

118. Hillman Jackson J, Clements D, Blakenberg D, Taylor J, Nekrutenko A, Team G: Using galaxy to perform large-scale interactive data analyses. Curr Protoc Bioinform 2012, 38:10.5.1-10.5.47.

119. Szklarczyk D, Franceschini A, Kuhn M, Simonovic M, Roth A, Minguez P, Doerks T, Stark M, Muller J, Bork P, et al: The STRING database in 2011: functional interaction networks of proteins, globally integrated and scored. Nucleic Acids Res 2010, 39:D561-D568.

doi:10.1186/1471-2164-14-694

Cite this article as: Lamont et al: Host-Mycobacterium avium subsp. paratuberculosis interactome reveals a novel iron assimilation mechanism linked to nitric oxide stress during early infection. BMC Genomics 2013 14:694.

\section{Submit your next manuscript to BioMed Central and take full advantage of:}

- Convenient online submission

- Thorough peer review

- No space constraints or color figure charges

- Immediate publication on acceptance

- Inclusion in PubMed, CAS, Scopus and Google Scholar

- Research which is freely available for redistribution 